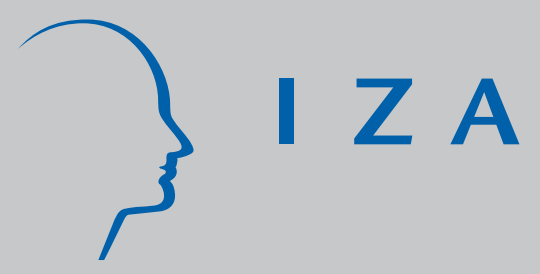

IZA DP No. 2558

Growth, Development, and Technological Change

Volker Grossmann

Thomas M. Steger

J anuary 2007 


\title{
Growth, Development, and Technological Change
}

\author{
Volker Grossmann \\ University of Fribourg, CESifo and IZA
}

Thomas M. Steger

ETH Zurich and CESifo

Discussion Paper No. 2558
January 2007

IZA
P.O. Box 7240
53072 Bonn
Germany

Phone: +49-228-3894-0

Fax: +49-228-3894-180

E-mail: iza@iza.org

Any opinions expressed here are those of the author(s) and not those of the institute. Research disseminated by IZA may include views on policy, but the institute itself takes no institutional policy positions.

The Institute for the Study of Labor (IZA) in Bonn is a local and virtual international research center and a place of communication between science, politics and business. IZA is an independent nonprofit company supported by Deutsche Post World Net. The center is associated with the University of Bonn and offers a stimulating research environment through its research networks, research support, and visitors and doctoral programs. IZA engages in (i) original and internationally competitive research in all fields of labor economics, (ii) development of policy concepts, and (iii) dissemination of research results and concepts to the interested public.

IZA Discussion Papers often represent preliminary work and are circulated to encourage discussion. Citation of such a paper should account for its provisional character. A revised version may be available directly from the author. 
IZA Discussion Paper No. 2558

January 2007

\section{ABSTRACT}

\section{Growth, Development, and Technological Change*}

The theory of endogenous technical change has deeply contributed to our understanding of the fundamental sources of economic growth and development. In this chapter we survey important contributions in the field by focussing on the basic structure of endogenous growth models with horizontal as well as vertical innovation and emphasizing important implications for growth policy. We address issues like the scale effect problem, directed technological change to understand the evolution of wage inequality, long-run divergence between the innovating North and the imitating South due to inappropriate technology in the South, the relationship between trade and growth, competition and R\&D, and the role of imperfect capital markets for R\&D-based growth.

JEL Classification: $\quad$ O10, O30, O40

Keywords: endogenous technical change, economic growth, horizontal innovations, scale effects, vertical innovations

Corresponding author:

Volker Grossmann

Department of Economics

University of Fribourg

Bd. de Pérolles 90

$\mathrm{CH}-1700$ Fribourg

Switzerland

E-mail: volker.grossmann@unifr.ch

This chapter is prepared for the UNESCO EOLSS ENCYCLOPEDIA OF MATHEMATICAL SCIENCES/Mathematical Models in Economics. 


\section{Introduction}

Sustained and significant growth in average world per capita income started roughly with the first era of the industrial revolution (Jones, 2005, section 5). There is little doubt that technological progress through process innovations played the key role in initiating, accelerating, and sustaining economic growth in the modern era (e.g. Mokyr, 2005).

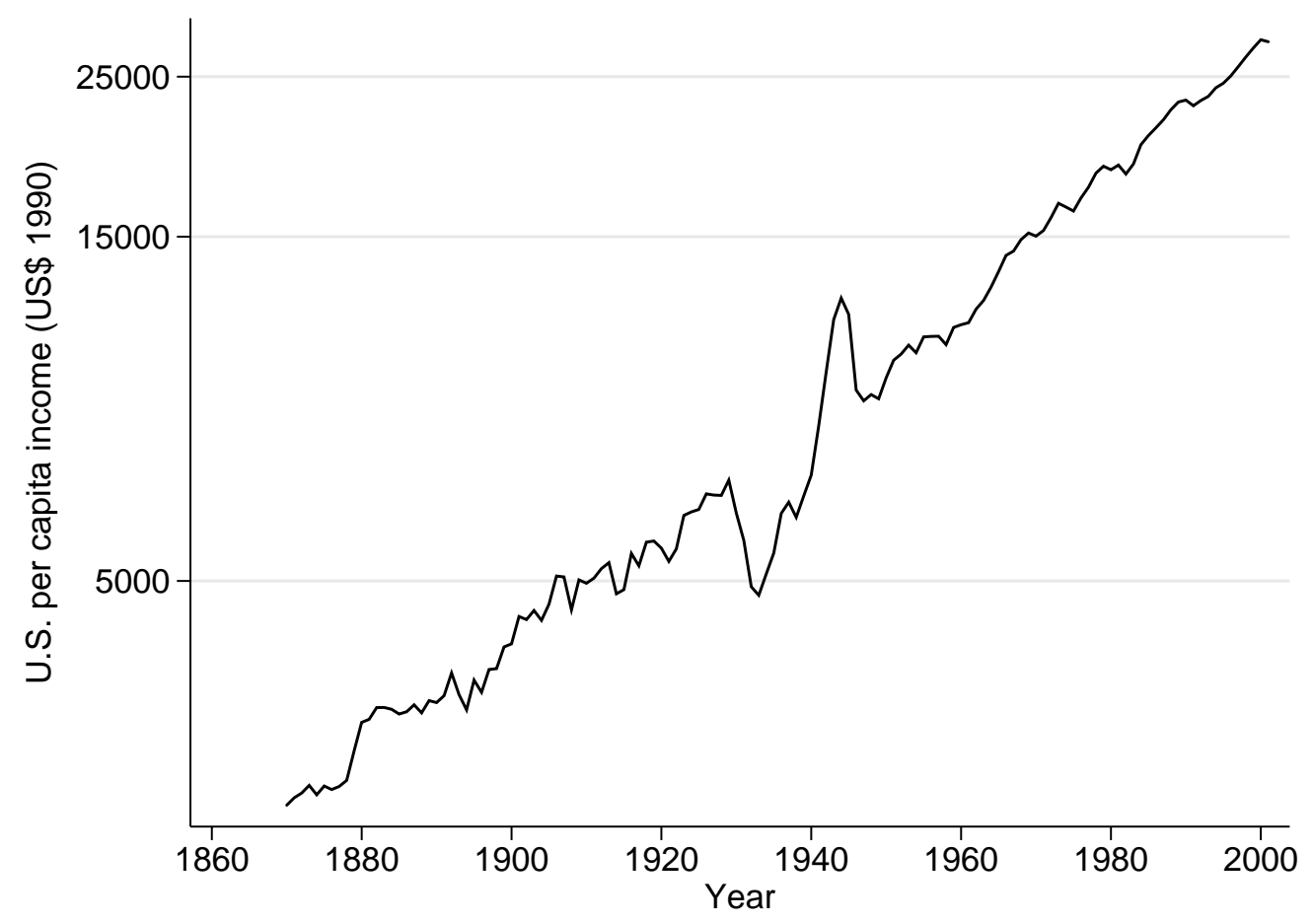

Figure 1: U.S. per capita GDP (log scale), 1870-2001. Note: Data from Maddison (2003).

Even according to neoclassical growth theory, long-run growth in income and physical capital per worker is entirely driven by productivity growth (more precisely, by the rate of labor-saving technological progress). Unfortunately, however, neoclassical growth models treat this growth rate as exogenous. They focus on transitional dynamics where the prime engine of income growth per worker is capital accumulation, depending on rates of investment and population growth in addition to the productivity growth rate. Thereby, neoclassical growth theory predicts falling growth rates within countries over time and convergence between countries, conditional on economic fundamentals. However, as 
shown in Fig. 1, historical evidence points to a relative stability of growth rates for more than a century in the U.S. Moreover, there is long-run divergence in per capita income between major regions in the world. ${ }^{1}$ Fig. 2 illustrates that economic divergence is not a recent phenomenon but started roughly with the beginning of the modern era, characterized by relatively fast growth in Western countries and slow growth in Africa in the last two centuries.

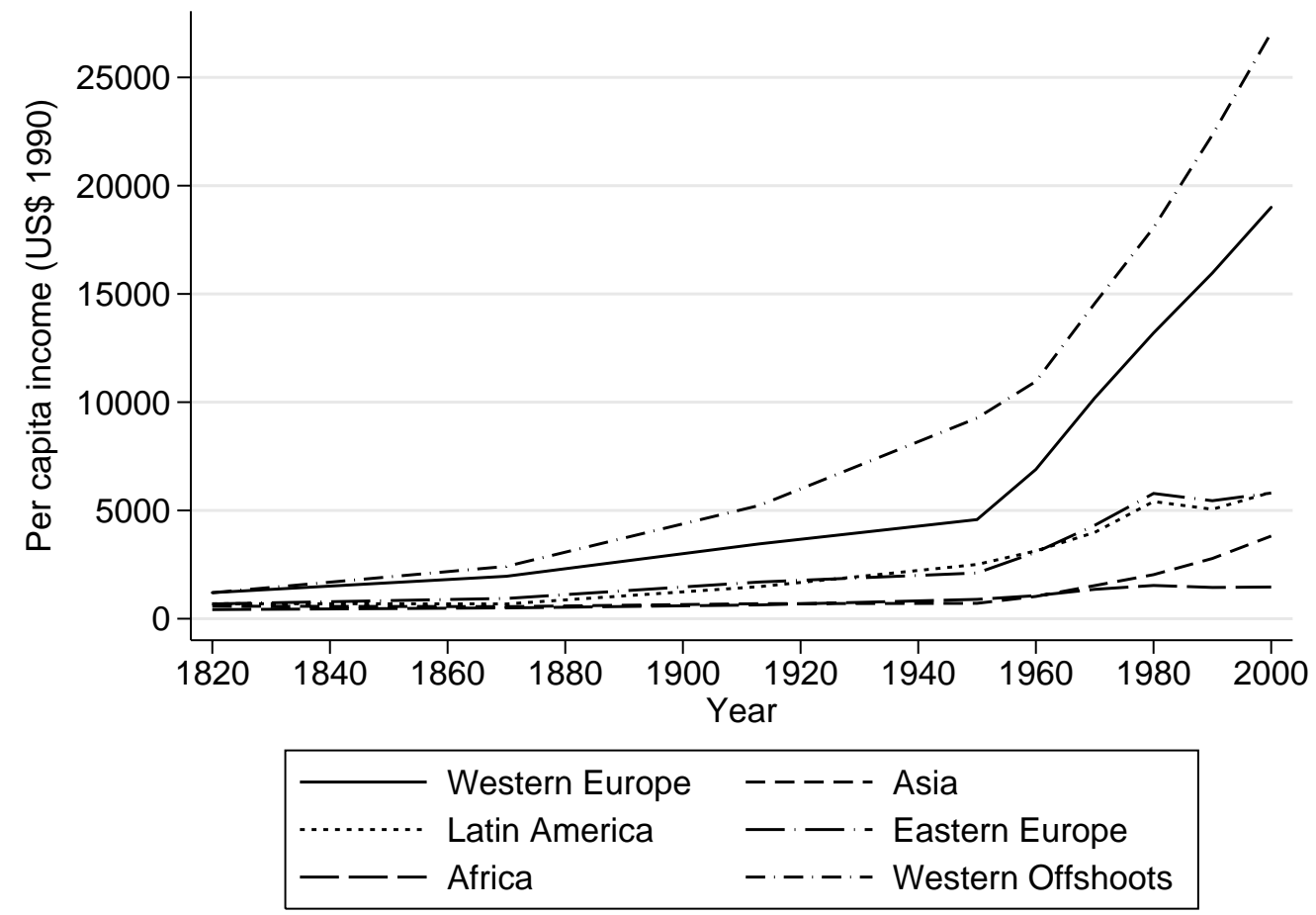

Figure 2: Divergence in per capita income, 1820-2001. Note: Data from Maddison (2003).

From this brief discussion, it is evident that models which endogenize technological change are highly desirable to understand the process of economic development in the long-run. In this survey, we outline in some detail important theoretical approaches in

\footnotetext{
${ }^{1}$ By allowing for accumulation of human capital in the basic model of Solow (1956), Mankiw, Romer and Weil (1992) argue that, using data from the period 1960-85, about 80 percent of the cross-country variation in income can be explained by focusing on the steady state of the augmented Solow-model, through differences in investment rates and the population growth rate. However, they do not address the overwhelming evidence on long-run divergence. Moreover, Bernanke and Gürkaynak (2001) find that, inconsistent with the Solow-model, the long-run growth rate depends on behavioral variables, particularly on the rate of investment of physical capital.
} 
which technological progress is driven by deliberate R\&D investments of private agents in response to market incentives. This literature, starting with Romer (1990), rests on the basic premise that intentional innovations require resources spent prior to both production of goods and product market competition. It thereby abandons the neoclassical paradigm of perfect competition and constant-returns to scale in the production process, which (as we point out in more detail in section 2) runs into the fundamental problem that it leaves no resources for the private sector to finance the search for innovations. The second premise of endogenous growth theory is that technological knowledge, in the form of a set of instructions how to produce goods and services (called "idea", "blueprint" or "design" in the literature), is a non-rival good; that is, an innovation can be used by others without diminishing the knowledge of the innovator. This implies that, without ways to exclude others from (some of) the newly created knowledge, in a large society no agent would have an incentive to incur any costs to innovate. (At least this is true when potential innovators are motivated alone by material benefits which accrue from applying the innovation.) An innovation would then be a pure public good, which suffers from underprovision when privately supplied (with zero provision when the number of agents goes to infinity). Intellectual property rights protection, which emerged in Britain already in the seventeenth century, may thus play an important role for stimulating innovations. ${ }^{2}$

In sum, endogenous growth theory captures the notion that knowledge accumulates through the arrival of new ideas which are an outcome of profit-oriented R\&D investments. By outlining basic approaches of this theory we demonstrate that it generates a wide range of interesting hypotheses and policy implications.

Our survey is structured into three main parts. In section 2, we present models

\footnotetext{
${ }^{2}$ The historical role of patents for the growth process is still under debate, however. For instance, Khan and Sokoloff (2001) show that the open patent system in the U.S. stimulated research activity in the nineteenth century. In contrast, Mokyr (2005) argues that the patent system in Britain did not play a major role in advancing technological knowledge during the first industrial revolution. Rather, nonmaterial benefits like honor and prestige to individual innovators provided important R\&D incentives. Moreover, accumulation of knowledge often rested on small and continuous technological improvements within firms created by skilled engineers who found productivity-enhancing ways to apply major inventions like the steam engine. As it may not be possible to immediately imitate such improvements, there are incentives to innovate even in absence of intellectual property rights.
} 
where growth is driven by new intermediate inputs ("horizontal innovations"), capturing specialization gains. The section builds on the seminal paper by Romer (1990). One major issue which has arisen from early models of endogenous technical change is the prediction of "scale effects" in growth rates, meaning that economies which possess a larger workforce that is capable to conduct $\mathrm{R} \& \mathrm{D}$ have higher per capita income growth rates. However, this result is inconsistent with the evidence that the U.S. economy is characterized by a fairly balanced (at least clearly non-accelerating) long-run growth path (recall Fig. 1) despite large increases in the number of employed scientists and engineers during the second half of the twentieth century (Jones, 1995a,b, 2005). We discuss how Jones $(1995 \mathrm{a}, \mathrm{b})$ eliminates the prediction of scale effects in growth rates. In his so-called semi-endogenous growth model, positive long-run growth is possible only if there is positive population growth. We then turn to three applications of the basic framework with horizontal innovations. First, following Acemoglu (1998, 2002), we allow for technological change which is directed to various skill types, thereby addressing the widely-discussed evidence on rising skill premia in many developed countries, despite increasing relative supply of skilled labor, in the last few decades. Second, we present a two-economy ("North" and "South") model, where economies differ in their relative endowment of skilled labor. We show that, although the South can imitate the technology of the innovating North at a small cost, output per worker is larger in the North, due to different factor endowments (Acemoglu and Zilibotti, 2001). Third, we highlight the role of horizontal innovations for the impact of liberalization of goods trade on economic growth (Rivera-Batiz and Romer, 1991). In section 3, we turn to models of "vertical innovations", where growth is driven by quality-improvements of intermediate goods. We first present a version of the "creative destruction" model by Aghion and Howitt (1992). As many models of endogenous technical change, in addition to scale effects in growth rates, the model predicts that higher market power is unambiguously conducive to $R \& D$ expenditure. As the scale effects prediction, this result is refuted by empirical evidence (e.g. Blundell, Griffith and van Reenen, 1999; Aghion, Bloom, Blundell, Griffith and Howitt, 2005, Aghion, Blundell, Griffith, Howitt and Prantl, 2006). Following Aghion and Howitt (2005), we therefore present a model with vertical innovations which modifies 
this result and has interesting implications for industrial R\&D policy. In section 4, we allow for horizontal differentiation in a model of vertical innovations, like in Dinopoulos and Thompson (1998), Peretto (1998), Segerstrom (1998), Young (1998). ${ }^{3}$ This class of models eliminates the scale effect in growth rates like semi-endogenous growth models but at the same time allows for positive income growth even in absence of population growth. Finally, we introduce borrowing constraints for financing R\&D into this model. The resulting model suggests an important role of credit market imperfections for longrun divergence, as recently emphasized by Aghion, Howitt and Mayer-Foulkes (2005).

\section{Horizontal Innovation}

The models considered in this section explain economic development to result from the interplay between capital accumulation and endogenous technological change. Private firms engage in $R \& D$ which results in new varieties of intermediate (or capital) goods. ${ }^{4}$ Since new intermediate goods are of the same quality as previously invented goods, technological change here takes the form of horizontal innovations.

\subsection{The Romer model}

\subsubsection{The challenge of modelling technological change}

The neoclassical growth model relies on exogenous technological progress as the ultimate engine of long-run economic growth (Solow, 1956; Swan, 1956). Romer (1990) was the first who formulated an explicit and rigorous growth model with endogenous technical progress. His analysis is based on three premises: (i) economic growth is driven by technological progress as well as capital accumulation; (ii) technological progress results from deliberate actions taken by private agents who respond to market incentives; (iii) technological knowledge is a non-rivalrous input. We will see below how these premises are formalized within the model.

\footnotetext{
${ }^{3}$ For simplicity, we focus on a discrete time version of this class of models, as in Young (1998).

${ }^{4}$ In the Grossman-Helpman (1991, chapter 3) model, not considered here, technological change takes the form of new varieties of consumer goods.
} 
Formulating a general equilibrium model with endogenous technological change, as required by premise (ii) above, is all but trivial. ${ }^{5}$ The major theoretical difficulty can be sketched as follows. Consider an economy producing a final output good $Y$ according to the production technology $Y=F(A, K, L)$, where $A$ denotes the state of technology, $K$ the stock of physical capital, $L$ labor input, and $F($.$) is C^{2}$ with $\frac{\partial F(.)}{\partial X}>0$ and $\frac{\partial^{2} F(.)}{\partial X^{2}}<0$ for all $X \in\{A, K, L\}$. It is further assumed that $F($.$) exhibits constant returns to$ scale (CRS) in capital and labor, i.e. $\lambda Y=F(A, \lambda K, \lambda L)$ for any $\lambda \geq 0$. Neoclassical theory relies on perfect competition such that all factors are rewarded according to their marginal product. This in turn implies that output is completely exhausted, i.e. $Y=F_{K}() K+.F_{L}()$.$L with F_{K}():.=\frac{\partial F(.)}{\partial K}$ denoting the marginal product of capital etc. Now it becomes obvious that any theory which rests on perfect competition together with CRS and should fulfill premise (ii) runs into a fundamental problem. Those agents who bring technical change about are assumed to react to market incentives and must therefore be rewarded somehow. Since output is, however, completely used up by paying wages to labor and rental prices to capital owners, nothing is left to reward researchers.

\subsubsection{The structure of the model}

We consider a simplified version of the Romer (1990) model in that there is only one type of labor. ${ }^{6}$ The household side is identical to the Ramsey model of optimal growth (see, for instance, Barro and Sala-i-Martin, 2004, chapter 2). On the production side there are three sectors: a final output sector, a producer durables sector, and a research sector.

Households. The economy is populated by a continuum of mass one identical households. Each household is endowed with $L$ units of labor services per unit of time, which are inelastically supplied (independent of the wage rate) to the market. Households are assumed to choose the time path of consumption $C(t)$ so as to maximize the present discounted value of an infinite utility stream $\int_{0}^{\infty} \frac{C(t)^{1-\sigma}-1}{1-\sigma} e^{-\rho t} d t$, where $\sigma>0$ and $\rho>0$ is

\footnotetext{
${ }^{5}$ Earlier contributions modelled technical progress as a by-product of capital accumulation (Arrow, 1962; Romer, 1986).

${ }^{6}$ Romer (1990) distinguishes between unskilled labor and skilled labor (human capital). This distinction is, however, not essential for the derived results; it merely relabels the relevant scale variable, as explained below.
} 
the time preference rate. The optimal consumption path obeys the well-known KeynesRamsey rule (KRR)

$$
\frac{\dot{C}(t)}{C(t)}=\frac{r(t)-\rho}{\sigma}
$$

where $\dot{C}(t):=d C(t) / d t$ denotes the rate of change of consumption and $r(t)$ is the interest rate in $t$.

Final output sector. Firms in the final output sector produce a homogenous good $Y$ that can be either consumed or used as an input in the production of differentiated capital goods. The market for the final output good is perfectly competitive. The technology is given $\mathrm{by}^{7}$

$$
Y=L_{Y}^{1-\alpha} \int_{0}^{A} x(i)^{\alpha} d i
$$

where $L_{Y}$ is the amount of labor devoted to $Y$-production, $x(i)$ is the amount of capital good $i \in[0, A]$, and $0<\alpha<1$. In equilibrium $x(i)=x$ for all $i$ and hence the above technology can be expressed as $Y=L_{Y}^{1-\alpha} A x^{\alpha}$. Moreover, if we define aggregate capital as $K:=A x$, one may write

$$
Y=\left(A L_{Y}\right)^{1-\alpha} K^{\alpha}
$$

This formulation shows that equ. (2) boils down to a Cobb-Douglas technology with labor-augmenting technical change and hence makes an important implication obvious: Even if one holds the total amount of capital $K=A x$ constant, an increase in the "number" of varieties $A$ boosts the productivity of labor. Hence, technology (2) captures the basic idea that specialization, as reflected by an increasing number of intermediate goods $x(i)$, makes the production process more and more efficient (Smith, 1776, Book I, chapter I; Ethier, 1982; Solow, 2000, chapter 9). Final output is chosen as the numeraire, its price is set equal to unity $p_{Y}=1$.

Producer durables sector. Producers in this sector manufacture differentiated capital goods $x(i)$, also labelled "producer durables" or simply "machines". As a technical and legal prerequisite for production, firms must at first purchase a blueprint (design). Technology (2) implies that the $x(i)$ are imperfect substitutes in $Y$-production; this as-

\footnotetext{
${ }^{7}$ The time index $t$ is often supressed to simplify the notation.
} 
sumption is crucial for monopolistic competition in the market for producer durables. ${ }^{8}$ As regards the production technology for $x(i)$, it is assumed that it takes one unit of "raw capital" (output not consumed) to create one unit of any type of durables (Romer, 1990, p. S82). ${ }^{9}$ The constant marginal production cost of $x$ therefore equals the interest rate $r$. As regards the institutional structure, it is assumed that $x$-producers rent their machines to $Y$-producers by charging a rental price.

R\&D sector. Firms in the research sector search for new and economically valuable ideas. An "idea" is a blueprint (design) for a new producer durable. The market for designs is perfectly competitive and characterized by free entry. ${ }^{10} \mathrm{R} \& \mathrm{D}$ is modelled as a deterministic process. The $\mathrm{R} \& \mathrm{D}$ technology is given by

$$
\dot{A}=\eta A L_{A}
$$

where $\dot{A}:=d A / d t$ denotes the rate of change in the number of blueprints $A$ per period of time $d t, L_{A}$ the amount of labor devoted to $\mathrm{R} \& \mathrm{D}$, and $\eta>0$. Notice that the productivity of researchers $L_{A}$ increases with technological knowledge $A$; see premise (iii) above. ${ }^{11}$

It should be noted that there is a double knife-edge restriction implicit in this formulation: (i) $\frac{\partial \ln \dot{A}}{\partial \ln A}=1$ and (ii) $\frac{\partial \ln \dot{A}}{\partial \ln L_{A}}=1$. The first is needed for sustained growth to be feasible. ${ }^{12}$ The second is required for a consistent microeconomic structure, i.e. a perfectly competitive market requires CRS in the single private input $L_{A}$. It is further assumed that, once a new idea is found, its producer obtains perfect and perpetual patent protection.

Equilibrium in the labor market requires $L=L_{A}+L_{Y}$. Equilibrium in the capital market requires that the household's financial capital equals the total physical capital

\footnotetext{
${ }^{8}$ The elasticity of substitution between any two $x(i)$ is $1<\frac{1}{1-\alpha}<\infty$.

${ }^{9}$ This modelling assumption is further explained in Rivera-Batitz and Romer (1991, p. 534): "This does not mean that consumption goods are directly converted into capital goods. Rather, the inputs needed to produce one unit of consumption are shifted from the production of consumption goods into the production of capital goods."

${ }^{10}$ In the words of Romer (1990, p. S85) "anyone engaged in research can freely take advantage of the entire existing stock of designs in doing research to produce new designs".

${ }^{11}$ Acemoglu (2002, p. 793) uses the phrase "current researchers "stand on the sholder of giants'."

${ }^{12}$ For a critical discussion of this linearity assumption see Solow (2000, chapter 9).
} 
employed by final output firms $K$.

The long run growth rate. The final output technology (3) indicates that, along the balanced growth path (BGP), this model is equivalent to a neoclassical growth model with labor-augmenting technical progress. This implies that the following relations must hold along the BGP: $\hat{Y}=\hat{K}=\hat{C}=\hat{A}=g$, where $\hat{X}:=\dot{X} / X$ for all $X \in\{Y, K, C, A\}$. Moreover, the R\&D technology (4) implies that the long run growth rate of $A$ is

$$
\hat{A}=\eta L_{A}^{*},
$$

where $L_{A}^{*}$ denotes the constant amount of labor devoted to R\&D. The economically interesting question then concerns the determination of $L_{A}^{*}$. This is the issue we consider at next.

\subsubsection{The decentralized solution}

To determine the long run growth rate of the market economy we start with the equilibrium condition stating that the wage rate of labor employed in $Y$-production $\left(w_{Y}\right)$ must equal the wage rate of labor employed in $\mathrm{R} \& \mathrm{D}\left(w_{R \& D}\right)$. The competitive wage rates in both sectors equal the respective value marginal product of labor. From (2) and (4) one therefore gets

$$
\begin{gathered}
w_{Y}=(1-\alpha) L_{Y}^{-\alpha} A x^{\alpha} \\
w_{R \& D}=p_{A} \eta A
\end{gathered}
$$

where $p_{A}$ is the price of a blueprint. Operating profits of the typical $x$-producer are $\pi=\left(p_{D}(x)-r\right) x$ with $p_{D}(x)$ denoting the demand price (or inverse demand function) of $x$, which is given by

$$
p_{D}(x)=\alpha L_{Y}^{1-\alpha} x^{\alpha-1}
$$

The typical $x$-producer faces constant marginal cost, equal to $r$, and a constant elasticity demand curve with a price elasticity equal to $\frac{1}{\alpha-1}<-1$. It is well known that, in this case, the optimal supply price is a mark-up over marginal cost according to $p_{S}=\frac{r}{\alpha}$. Moreover, using $r=\alpha p_{S}$ we have $\pi=\left(p_{D}-\alpha p_{S}\right) x$. From equilibrium in the 
$x$-market, $p_{D}=p_{S}=p$, and plugging (5) into the profit function one gets

$$
\pi=(1-\alpha) p x=(1-\alpha) \alpha L_{Y}^{1-\alpha} x^{\alpha} .
$$

Assuming that the economy grows along a BGP, which implies that both $\pi$ and $r$ are constant, the price of a blueprint may be expressed as $p_{A}=\frac{\pi}{r}$. Hence, the price of a blueprint may be written as $p_{A}=\frac{(1-\alpha) \alpha L_{Y}^{1-\alpha} x^{\alpha}}{r}$. Now evaluating the equilibrium condition $w_{Y}=w_{R \& D}$ yields ${ }^{13}$

$$
(1-\alpha) L_{Y}^{-\alpha} A x^{\alpha}=\frac{\eta A(1-\alpha) \alpha L_{Y}^{1-\alpha} x^{\alpha}}{r}
$$

which immediately gives $r=\eta \alpha L_{Y}$. Plugging $L_{Y}=L-L_{A}$ (labor market equilibrium) and $L_{A}=\frac{g}{\eta}$ (from (4)) into the preceding equation leads to a condition describing equilibrium on the supply side of the economy

$$
r=\eta \alpha L-\alpha g
$$

The economic reason for the negative relationship between $r$ and $g$ is that an increase in $r$ lowers $p_{A}=\frac{\pi}{r}$ and therefore R\&D firms employ a lower amount of labor. Equilibrium on the demand side is described by the KRR, equ. (1), which may be expressed as

$$
r=\sigma g+\rho
$$

The positive association between $r$ and $g$ captures the fact that an increase in $r$ motivates households to save more which boost growth. Solving (6) and (7) for $g$ yields $g=\frac{\eta \alpha L-\rho}{\sigma+\alpha} .{ }^{14}$ Since growth cannot become negative in this model, the long run growth rate of the

\footnotetext{
${ }^{13}$ This condition can be expressed as $\frac{\pi}{r}=\frac{w}{\eta A}$ and hence is equivalent to the free entry condition (implying zero profits) in the R\&D sector. To see this, note that under (4), profits are given by $P_{A} \eta A L_{A}-w L_{A}$ and use $P_{A}=\frac{\pi}{r}$.

${ }^{14}$ One can equivalently solve $(6)$ and $(7)$ for $r$ and then evaluate $r=\eta \alpha\left(L-L_{A}\right)$, which gives $L_{A}^{*}$. Plugging the result into $g=\hat{A}=\eta A L_{A}^{*}$ yields, of course, the same solution.
} 
market economy, denoted $g_{M}$, reads

$$
g_{M}=\left\{\begin{array}{cl}
\frac{\eta \alpha L-\rho}{\sigma+\alpha} & \text { for } \eta \alpha L>\rho \\
0 & \text { for } \eta \alpha L \leq \rho
\end{array} .\right.
$$

Long run growth obviously requires that the economy is large enough in the sense that $\eta \alpha L>\rho$. Moreover, the preceding solution shows a scale effect since, provided that $\eta \alpha L>\rho$, larger economies (with size being measured by $L$ ) do grow at a higher rate. The economic reason for this scale effect implication is that, along the BGP, a constant fraction of the labor force is devoted to R\&D. More researchers produce more knowledge, which in turn improves the productivity of the R\&D sector such that long run growth accelerates. This effect does, however, depend critically on the strength of the intertemporal knowledge spill-over, as will be discussed below.

\subsubsection{Market imperfections and policy implications}

So far we have focused on the decentralized economy. Turning to the social planner's solution, it can be readily shown that the optimal long run growth rate, $g_{S}$, is given by (Chiang, 1992)

$$
g_{S}=\left\{\begin{array}{cc}
\frac{\eta L-\rho}{\sigma} & \text { for } \eta L>\rho \\
0 & \text { for } \eta L \leq \rho
\end{array} .\right.
$$

Comparing this result to (8) shows that $g_{M}<g_{S}$. The market economy grows at a pace which is too low compared to the social optimum. This is due to two imperfections inherent in the market economy, which bias the private allocation decisions (Jones and Williams, 2000; Steger, 2005): First, the R\&D technology (4) exhibits an intertemporal knowledge spill-over since the productivity of current researcher $L_{A}$ increases with the stock of knowledge, as measured by $A$, which has been accumulated in the past. This social benefit is not reflected in the market price for designs $p_{A}=\frac{\pi}{r}$ and, consequently, R\&D incentives are too low. Second, the typical producer durable firm realizes a monopoly profit by selling a differentiated capital good. It cannot, however, appropriate the entire "consumer surplus". The gain to society resulting from a new innovation is 
larger than the private profits earned by the monopolist. This static distortion leads once more to a price of blueprints which falls short of its social value. Hence, the Romer (1990) model unambiguously exhibits underinvestment in R\&D. ${ }^{15}$ This basic implication is in line with empirical studies on the gap between the private and the social rate of return on R\&D. Griliches (1991) reviews this literature and reports social rates of return of about 40 to 60 percent, which are much higher than private rates of return.

What are appropriate public policies to correct these market failures? One possible scheme of public policies is as follows. The positive knowledge spill-over can be neutralized by a subsidy on the sales of blueprints. The "consumer surplus" effect can be corrected by subsidizing the sales of producer durables (Steger, 2005, section II).

\subsection{Semi-endogenous R\&D-based models}

Jones (1995a,b, 2002) has argued that the scale effect implication inherent in the first generation of R\&D-based growth models (Romer, 1990; Grossman and Helpman, 1991, chapter 3; Aghion and Howitt, 1992) is empirically problematic. Using time series evidence for the G5-group of industrialized economies he shows that the number of scientists and engineers has risen drastically during the post-WWII period. Even the relation of scientists and engineers to the total number of employees has increased in the G5-group as a whole. During the same time period, however, the growth rate of GDP per capita as well as the TFP growth rate was roughly stationary, or at least non-increasing, in the U.S. (cf. Figure 1 above) and in the G5 group (see also Jones, 2005, section 5). ${ }^{16}$

This empirical pattern is clearly at odds with the basic R\&D-based growth model described above. Jones (1995a,b) has accordingly modified the Romer (1990) model to eliminate the scale effect. Another major result of this line of research is the finding of

\footnotetext{
${ }^{15}$ There are other R\&D-based growth models with positive and negative R\&D externalities such that the amount of resources devoted to R\&D might be too high in the market equilibrium (Jones and Williams, 2000; Steger, 2005; Strulik, 2005). Also horizontal innovation models do not capture another important externality associated with private R\&D, namely the business stealing effect (see Section 3 of this article).

${ }^{16}$ The evidence on the scale effect is mixed, however. Kremer (1993) argues that there is a positive scale effect at the level of the world when considering the very long run (one million B.C. until present). Backus et al. (1992) find mixed results within a cross-sectional studies using different measures for the scale of an economy (e.g. aggregate GDP; manufacturing output; number of scientists, engineers and technicians; R\&D expenditure).
} 
policy ineffectiveness. Public policy is unable to control the long run growth rate. For this reason Jones used the phrase "semi-endogenous growth model".

The Jones (1995a,b) model is basically identical to the Romer (1990) with one important modification. The double knife-edge restriction $\frac{\partial \ln \dot{A}}{\partial \ln A}=1$ and $\frac{\partial \ln \dot{A}}{\partial \ln L_{A}}=1$ inherent in the R\&D technology, see (4) above, is relaxed by postulating the following (sectoral) R\&D technology

$$
\dot{A}=\eta A^{\phi} L_{A}^{\gamma},
$$

where $0<\phi<1,0<\gamma \leq 1 .{ }^{17}$ The total amount of labor is assumed to grow exponentially, i.e. $L(t)=L_{0} e^{n t}$, where $n$ denotes the growth rate of the labor force, and $L_{0}>0$. As before, along a BGP we have $\hat{y}=\hat{k}=\hat{c}=\hat{A}=g$, where small letters denote per capita quantities.

The determination of the long run growth rate is very simple in this model. Divide both sides of equ. (10) by $A$, and use $L_{A}=\frac{L_{A}}{L} L$, to get

$$
\hat{A}=\frac{\dot{A}}{A}=\eta A^{\phi-1}\left(\frac{L_{A}}{L}\right)^{\gamma} L^{\gamma}
$$

Taking logarithms on both sides yields

$$
\log (\hat{A})=\log (\eta)+(\phi-1) \log (A)+\gamma \log \left(\frac{L_{A}}{L}\right)+\gamma \log (L)
$$

Forming the time derivative and noting that (i) $\hat{A}=$ const. and $\frac{L_{A}}{L}=$ const. along a BGP by definition and (ii) $\frac{d \log (A)}{d t}=\hat{A}$ etc. one gets

$$
\hat{A}=\frac{\gamma n}{1-\phi}
$$

The scale effect has obviously been removed from the model. Instead, the growth rate of per capita income $g=\hat{y}=\hat{A}$ is now proportional to the growth rate of the labor force $n$. Here we have an important implication for a number of industrialized economies

\footnotetext{
${ }^{17}$ Notice that $\gamma<1$ implies decreasing returns to labor at the sectoral level. This formulation is compatible with CRS at the level of the firm and hence with perfect competition in the R\&D sector in the presence of negative duplication externalities (i.e. the possibility that decentralized R\&D might lead to redundancy).
} 
which experience a decline in $n$. Growth is semi-endogenous: On the one hand, it is endogenous because growth still results from deliberate actions taken by private agents who respond to market incentives. On the other hand, it is exogenous to the extent that public policy cannot control the balanced growth rate. ${ }^{18}$ In fact, the long run growth rate is proportional to the growth rate of labor with the factor of proportionality $\frac{\gamma}{1-\phi}$ being determined by the characteristics of the R\&D technology. ${ }^{19}$

Finally it should be noted that Eicher and Turnovsky (1999) have formulated a more general semi-endogenous R\&D-based growth model (which they label non-scale growth model), showing that the long run growth rate is in general determined by the characteristics of both the $R \& D$ technology and the final output technology.

\subsection{Directed technical change}

The R\&D-based endogenous growth models considered so far are characterized by a single R\&D process. There are, however, a number of important topics (like biased technological change and the evolution of wage inequality or the consequences of international trade on the direction of technological change), which require a setup with multiple $R \& D$ processes such that technological change can be directed at different factors of production. Hence, we next turn to a model with two sectors, two production factors and two R\&D processes to study the direction of technical change. This approach is due to Acemoglu (1998, 2002); see also Gancia and Zilibotti (2005). The model considered here is a direct extension of the Romer (1990) model.

\subsubsection{The basic model setup}

Final output sector. There is a large number of mass one of identical firms who produce a homogenous final output $Y$ under perfect competition using the following

\footnotetext{
${ }^{18}$ The long run growth rate of the market economy and the socially controlled economy coincide. In this sense there is simply no need for public policy to intervene. Nonetheless, along the BGP, the market economy grows at a lower level compared to the socially controlled economy.

${ }^{19}$ Neither do preferences nor the parameters of final output technology play any role. These parameters do nonetheless affect the level of the BGP.
} 
constant elasticity of substitution (CES) technology

$$
Y=\left(\gamma Y_{L}^{\frac{\varepsilon-1}{\varepsilon}}+(1-\gamma) Y_{H}^{\frac{\varepsilon-1}{\varepsilon}}\right)^{\frac{\varepsilon}{\varepsilon-1}}
$$

where $Y_{L}$ and $Y_{H}$ are intermediate inputs, $0<\gamma<1$ is a constant parameter, and $0<\varepsilon<\infty$ determines the degree of substitution between $Y_{L}$ and $Y_{H}$ in $Y$-production (as explained below). The final output good can be used for consumption $(C)$, as an input in the production of machines $(I)$, or as an input in R\&D $(R)$. The economy's resource constraint accordingly reads $Y \leq C+I+R$.

Intermediate goods sector. There is a large number of mass one of identical $Y_{L^{-}}$ producers and a large number of mass one of identical $Y_{H}$-producers. Production takes place under perfect competition. The production technologies for the two intermediate goods $Y_{L}$ and $Y_{H}$ are given by

$$
\begin{gathered}
Y_{L}=L^{1-\alpha} \int_{0}^{A_{L}} x_{L}(i)^{\alpha} d i \\
Y_{H}=H^{1-\alpha} \int_{0}^{A_{H}} x_{H}(i)^{\alpha} d i,
\end{gathered}
$$

where $L$ denotes unskilled labor, $H$ skilled labor, and $0<\alpha<1$ a constant parameter. Notice that the production of $Y_{L}$ is assumed to be labor intensive, whereas the production of $Y_{H}$ is human capital intensive. There are two type of producer durables ("machines"), namely $x_{L}(i)$ with $i \in\left[0, A_{L}\right]$ and $x_{H}(i)$ with $i \in\left[0, A_{H}\right]$. Machines of type $x_{L}(i)$ are combined with labor in $Y_{L}$-production, whereas machines $x_{H}(i)$ are combined with human capital in $Y_{H}$-production. This formulation captures the basic idea that different input factors $(L$ and $H)$ are combined with different machines and, hence, technological progress (the introduction of new machines) might favor one factor more than others. For instance, the introduction of the assembly line primarily increased the productivity of unskilled labor, whereas the introduction of computers favored human capital.

As before, technical change enhances the spectrum of available machines. The important point to notice is that the range of machines that can be used with labor is $A_{L}$, whereas the range of machines that can be used with human capital is $A_{H}$. Therefore, 
in this setup, technical change is either directed at labor (i.e. increasing $A_{L}$ ) or directed at human capital (i.e. enhancing $A_{H}$ ).

Machines sector. Firms in this sector conduct R\&D and once a firm has found a blueprint for a new machine it starts production and marketing. There is a large number of potential suppliers and free entry into this sector. Once a design for a new machine is found, the successful firm is granted perfect and infinite patent protection and thereby becomes a "technology monopolist". The market for machines hence is monopolistically competitive. Machines $\left(x_{L}\right.$ and $\left.x_{H}\right)$ are rented to intermediate goods producers by charging a rental price $\left(p_{x_{L}}, p_{x_{H}}\right)$. For simplicity, it is assumed that all machines depreciate fully after use. ${ }^{20}$ The marginal production cost is the same for all machines and equal to $\psi$ in terms of the final good. The $R \& D$ technologies are given by

$$
\begin{gathered}
\dot{A}_{L}=\eta_{L} R_{L} \\
\dot{A}_{H}=\eta_{H} R_{H},
\end{gathered}
$$

where $\eta_{L}, \eta_{H}>0$ and $R_{L}$ is spending on R\&D (in terms of final output) for new $x_{L^{-}}$ machines and $R_{H}$ is spending on R\&D for $x_{H}$-machines. This specification, labelled as lab-equipment approach, departs from the original Romer model in that final output is used instead of labor as an input in $R \& D$.

\subsubsection{Equilibrium}

The typical $Y$-producer takes the output price $p_{Y}$ and input prices $\left(p_{L}\right.$ and $\left.p_{H}\right)$ as given. Profit maximization then implies that an optimal production plan is characterized by

$$
\frac{p_{H}}{p_{L}}=\frac{1-\gamma}{\gamma}\left(\frac{Y_{H}}{Y_{L}}\right)^{-\frac{1}{\varepsilon}} \text {, }
$$

i.e. the ratio of input prices (LHS of (13)) must equal the marginal rate of substitution (RHS of (13)). Here one recognizes that the elasticity of substitution between $Y_{H}$ and

\footnotetext{
${ }^{20}$ Hence, the machines $x_{L}(i)$ and $x_{H}(i)$ are similar to intermediate goods which are used up in the production process. Notice that the original Romer (1990) assumes the opposite polar case of no depreciation.
} 
$Y_{L}$ is $\frac{\partial \ln \left(Y_{H} / Y_{L}\right)}{\partial \ln \left(p_{H} / p_{L}\right)}=-\varepsilon$. The final output good $Y$ is chosen as the numeraire and hence we $\operatorname{set}^{21}$

$$
p_{Y}=\left(\gamma^{\varepsilon} p_{L}^{1-\varepsilon}+(1-\gamma)^{\varepsilon} p_{H}^{1-\varepsilon}\right)^{\frac{1}{1-\varepsilon}}=1
$$

The producers of intermediate goods $\left(Y_{L}\right.$ and $\left.Y_{H}\right)$ maximize profits

$$
\begin{gathered}
p_{L} Y_{L}-w_{L} L-\int_{0}^{A_{L}} x_{L}(i) p_{x_{L}}(i) d i \\
p_{H} Y_{H}-w_{H} H-\int_{0}^{A_{H}} x_{H}(i) p_{x_{H}}(i) d i
\end{gathered}
$$

taking output prices $\left(p_{L}\right.$ and $\left.p_{H}\right)$ and input prices $\left(p_{x_{L}}, p_{x_{H}}, w_{L}, w_{H}\right)$ as given. Noting (11) and (12) this yields the following demand curves for machines

$$
\begin{gathered}
x_{L}(i)=\left(\frac{\alpha p_{L}}{p_{x_{L}}^{D}(i)}\right)^{\frac{1}{1-\alpha}} L \\
x_{H}(i)=\left(\frac{\alpha p_{H}}{p_{x_{H}}^{D}(i)}\right)^{\frac{1}{1-\alpha}} H,
\end{gathered}
$$

where $p_{x_{L}}^{D}(i)$ and $p_{x_{H}}^{D}(i)$ denote demand prices. Intermediate goods producer accordingly rent more machines, the higher product prices $\left(p_{L}\right.$ and $\left.p_{H}\right)$, the larger the amount of complementary factors employed $(L$ and $H)$ and the lower the rental price of machines $\left(p_{x_{L}}^{D}, p_{x_{H}}^{D}\right)$. Operating profits of the typical technology monopolists are given by

$$
\begin{gathered}
\pi_{L}=\left(p_{x_{L}}^{S}-\psi\right) x_{L}=\left(\frac{\psi}{\alpha}-\psi\right)\left(\frac{\alpha^{2}}{\psi}\right)^{\frac{1}{1-\alpha}} p_{L}^{\frac{1}{1-\alpha}} L \\
\pi_{H}=\left(p_{x_{H}}^{S}-\psi\right) x_{H}=\left(\frac{\psi}{\alpha}-\psi\right)\left(\frac{\alpha^{2}}{\psi}\right)^{\frac{1}{1-\alpha}} p_{H}^{\frac{1}{1-\alpha}} H
\end{gathered}
$$

where the second equalities follow from the demand curves (15) and (16), noting that the optimal supply price is a mark up over marginal cost according to $p_{x_{L}}^{S}=\frac{\psi}{\alpha}$ and $p_{x_{H}}^{S}=\frac{\psi}{\alpha}$, and using $p_{x_{L}}^{S}=p_{x_{L}}^{D}$ and $p_{x_{L}}^{S}=p_{x_{L}}^{D}$ (equilibrium in the machine markets). The relative

\footnotetext{
${ }^{21}$ See Solow (2000, chapter 10) on the determination and interpretation of the CES price index in the Dixit-Stiglitz framework.
} 
profitability of R\&D directed at human capital $H$ and labor $L$ can hence be expressed as

$$
\frac{\pi_{H}}{\pi_{L}}=\left(\frac{p_{H}}{p_{L}}\right)^{\frac{1}{1-\alpha}} \frac{H}{L} .
$$

The incentive to engage in $A_{H^{-}}$expanding $\mathrm{R} \& \mathrm{D}$ relative to the incentive to conduct $A_{L}$-enhancing $\mathrm{R} \& \mathrm{D}$ comprises two components. The first term gives the price effect: there is a greater incentive to develop technologies producing more expensive goods. The second term is the market size effect: the incentive to develop a new technology is proportional to the number of workers that will be using it.

We now turn to the ratio of $A_{H}$ and $A_{L}$ along the BGP. For $A_{H} / A_{L}$ to be constant, as required for balanced growth, there must be innovating firms in both machine sectors. This requires that it is equally profitable to invest in $A_{H^{-}}$expanding and $A_{L}$-expanding R\&D, i.e. $\eta_{H} \pi_{H}=\eta_{L} \pi_{L}$. From this condition the constant ratio of technologies can be shown to read as follows (for details see the appendix)

$$
\frac{A_{H}}{A_{L}}=\left(\frac{1-\gamma}{\gamma}\right)^{\varepsilon}\left(\frac{\eta_{H}}{\eta_{L}}\right)^{\theta}\left(\frac{H}{L}\right)^{\theta-1},
$$

where $\theta:=1+(\varepsilon-1)(1-\alpha)$ is the (derived) elasticity of substitution between $H$ and $L$ (as will become clear below). ${ }^{22}$ As long as human capital and labor are strong substitutes $(\theta>1)$, an increase in the supply of one factor will induce more innovation directed to that specific factor. The reason is that, as long as $\theta>1$, the market size effect dominates the price effect. As a consequence, technological change is biased towards the abundant factor. The reverse holds true for $\theta<1$. In this case, the price effect dominates the market size effect and technological change favors the scarce factor.

By determining the equilibrium interest rate from the condition that profits in the machines sector equal zero and plugging the result into the KRR, the long run growth rate can be shown to read (for details see the appendix)

$$
g=\frac{1}{\sigma}(r-\rho)
$$

\footnotetext{
${ }^{22}$ Notice that $\theta>(<) 1$ requires $\varepsilon>(<) 1$.
} 


$$
\text { with } \quad r:=\omega\left(\gamma^{\varepsilon}\left(\eta_{L} L\right)^{\theta-1}+(1-\gamma)^{\varepsilon}\left(\eta_{H} H\right)^{\theta-1}\right)^{\frac{1}{\theta-1}}
$$

where $\omega:=\left(\frac{\psi}{\alpha}-\psi\right)\left(\frac{\alpha^{2}}{\psi}\right)^{\frac{1}{1-\alpha}}$. As usual, long run growth decreases with the time preference rate $\rho$. It increases with the intertemporal elasticity of substitution $\frac{1}{\sigma}$ and the interest rate $r$. The interesting point to notice here is that the interest rate (hence the growth rate) is determined by the characteristics of all production technologies (final output, machines, and R\&D) as well as by factor endowments $(H$ and $L) .{ }^{23}$

To see the implications of directed technological change for factor prices, one can solve for $w_{H}$ and $w_{L}$ taking technology $\left(A_{H}\right.$ and $\left.A_{L}\right)$ as given (for details see the appendix)

$$
\frac{w_{H}}{w_{L}}=\left(\frac{1-\gamma}{\gamma}\right)^{\frac{\varepsilon}{\theta}}\left(\frac{A_{H}}{A_{L}}\right)^{\frac{\theta-1}{\theta}}\left(\frac{H}{L}\right)^{-\frac{1}{\theta}} .
$$

This relation shows that the (short run) elasticity of substitution between $H$ and $L$ is $\frac{\partial \ln (H / L)}{\partial \ln \left(w_{H} / w_{L}\right)}=-\theta$. The relative factor reward is decreasing in the relative factor supply. This is due to the usual substitution effect. Moreover, when $\theta>1$ a greater skill bias in technology $A_{H} / A_{L}$ increases relative factor rewards and vice versa.

We finally look at the implications for relative factor prices in the long run, i.e. when technology is considered as being endogenous. Inserting (20) into (23) gives a reduced form solution for the relative factor price

$$
\frac{w_{H}}{w_{L}}=\left(\frac{\eta_{H}}{\eta_{L}}\right)^{\theta-1}\left(\frac{1-\gamma}{\gamma}\right)^{\varepsilon}\left(\frac{H}{L}\right)^{\theta-2}
$$

This equation shows that, as long as $\theta>2$, an increase in relative supply of skilled labor can go hand in hand with an increase in the skill premium $\left(\frac{w_{H}}{w_{L}}\right)$. This is due to endogenous biased technological change towards the more abundant factor since the market size effect is sufficiently strong. Hence, as argued by Acemoglu (1998), this model provides a potential explanation for the empirical observation of a rise in the skill premium in the U.S. during the period 1960-90 despite an increase in the relative supply of skilled labor. ${ }^{24}$

\footnotetext{
${ }^{23}$ Hence this model also features a scale effect.

${ }^{24}$ For a comprehensive discussion of "technical change and labor market inequalities" see Hornstein,
} 


\subsection{Appropriate technology and development}

The previous section has demonstrated that the directed-technical-change approach can be used to understand the evolution of wage inequality within an economy. This approach can also be employed to understand the fundamental causes of the sustained income gap between industrialized and less developed countries. ${ }^{25}$ An important reason for sustained underdevelopment is due to "inappropriate technologies". The model developed by Acemoglu and Zilibotti (2001) assumes that, quite realistically, less developed economies imitate the technologies developed in industrialized countries. Provided that intellectual property rights cannot be enforced in underdeveloped economies, technologies are designed according to the fundamentals of the rich industrialized countries and therefore are not optimal when applied in poor underdeveloped economies.

\subsubsection{The basic model setup}

There are two sets of economies, the North and the South. The North is innovative, as in the previous sections. The South does not innovate but adopts technologies innovated in the North. Intellectual property rights cannot be enforced in the South. There is no trade between the North and the South. The model is similar to the directed technical change model. There are three sectors, namely a final output sector, an intermediate goods sector, and a machines sector.

Final output sector. This sector is perfectly competitive. Firms assemble a range of intermediate goods $y(i)$ with $i \in[0,1]$ to produce final output $Y$ according to

$$
Y=\exp \left[\int_{0}^{1} \ln y(i) d i\right]
$$

This somewhat unusual production function can be viewed as a symmetric Cobb-Douglas function. Final output can be used for consumption $(C)$, investment $(I)$, or as an input in $\mathrm{R} \& \mathrm{D}(X)$. The resource constraint therefore is $Y \leq C+I+X$. Moreover, final output good is chosen as the numeraire good such that $p_{Y}=1$.

\footnotetext{
Krusell and Violante (2005).

${ }^{25}$ Caselli (2005) reviews the development accounting literature, which aims at explaining the empirical causes for international differences in per capita incomes.
} 
Intermediate goods sector. There is a continuum of heterogenous sectors producing intermediate goods $y(i)$. Each intermediate good $y(i)$ can be produced with unskilled labor $l$, skilled labor $h$, and machines. However, each sector has a different production technology. The key assumption is that some machines can only be used with unskilled labor, while some other machines can only be used with skilled labor. More specifically, the production technology for good $y(i)$ is of the following form

$$
y(i)=[(1-i) l(i)]^{1-\alpha} \int_{0}^{A_{L}} x_{L}^{\alpha}(i, \gamma) d \gamma+[i h(i)]^{1-\alpha} \int_{0}^{A_{H}} x_{H}^{\alpha}(i, \nu) d \nu
$$

where $l(i)$ and $h(i)$ are the quantities of unskilled and skilled labor employed in sector $i, x_{L}(i, \gamma)$ is the quantity of $x_{L}$-machines of type $\gamma \in\left[0, A_{L}\right]$ employed in sector $i$, and $x_{H}(i, \nu)$ is the quantity of $x_{H}$-machines of type $\nu \in\left[0, A_{H}\right]$ in sector $i$, respectively. Notice the term $(1-i)$, associated with unskilled labor $l(i)$, and the term $i$, attached to skilled labor $h(i)$, which denote exogenous technology-specific and sector-specific productivities. In sectors with a high $i \in[0,1]$ unskilled labor (which can only be combined with $x_{L^{-}}$ machines) has a low productivity but skilled labor (which can only be combined with $x_{H}$-machines) has a high productivity, and vice versa.

Machines sector. Firms in this sector either innovate (in the North) or imitate (in the South). Successful innovators in the North are granted perfect patent protection in the Northern market. Once a blueprint has been invented or copied, firms start to manufacture and market differentiated machines as technology monopolists. There is a large number of potential entrants and there is free entry. For reasons which become clear below, the unit production cost are normalized to $\alpha^{2}$.

\subsubsection{Equilibrium}

The North. Each firm in the intermediate goods sector maximizes profits taking the output price $p(i)$ and input prices $\left(w_{L}, w_{H}, p_{x_{L}}, p_{x_{H}}\right)$ as given. The resulting sectoral demand curves for $x_{L}$-machines and $x_{H}$-machines are as follows (due to symmetry the 
indices $\gamma$ and $\nu$ can be omitted)

$$
\begin{gathered}
x_{L}(i)=(1-i) l(i)\left(\alpha \frac{p(i)}{p_{x_{L}}^{D}}\right)^{\frac{1}{1-\alpha}} \\
x_{H}(i)=i h(i)\left(\alpha \frac{p(i)}{p_{x_{H}}^{D}}\right)^{\frac{1}{1-\alpha}} .
\end{gathered}
$$

Since marginal cost of machine production are equal to $\alpha^{2}$, the optimal supply price is $p_{x_{L}}^{S}=p_{x_{H}}^{S}=\alpha$. Setting $p_{x_{L}}^{D}=p_{x_{L}}^{S}=\alpha$ and $p_{x_{H}}^{D}=p_{x_{H}}^{S}=\alpha$ in (27) and (28) and using (26) yields an indirect production function for intermediate goods

$$
y(i)=p(i)^{\frac{\alpha}{1-\alpha}}\left[A_{L}(1-i) l(i)+A_{H} i h(i)\right] .
$$

This formulation shows very clearly that, given $A_{L}$ and $A_{H}$, the productivity of unskilled labor decreases with the sector index $i$, whereas the productivity of skilled labor increases with the sector index. This implies that there is a critical threshold $J \in[0,1]$ such that all sectors $i \leq J$ will employ unskilled labor only (together with $x_{L}$-machines), whereas all sectors $i>J$ will employ skilled labor only (together with $x_{H}$-machines).

The total profit earned by the typical $x_{L}$-monopolist is given by $\pi_{L}=\left(p_{x_{L}}^{S}-\right.$ $\left.\alpha^{2}\right) \int_{0}^{1} x_{L}(i) d i$; for $x_{H}$-monopolist we have $\pi_{H}=\left(p_{x_{H}}^{S}-\alpha^{2}\right) \int_{0}^{1} x_{H}(i) d i$. Noting $(27)$ and (28) together with $p_{x_{L}}^{D}=p_{x_{L}}^{S}=\alpha$ and $p_{x_{H}}^{D}=p_{x_{H}}^{S}=\alpha$ equilibrium profits read as follows

$$
\begin{gathered}
\pi_{L}=(1-\alpha) \alpha \int_{0}^{1} p(i)^{\frac{1}{1-\alpha}}(1-i) l(i) d i \\
\pi_{H}=(1-\alpha) \alpha \int_{0}^{1} p(i)^{\frac{1}{1-\alpha}} i h(i) d i .
\end{gathered}
$$

The prices of intermediate goods are given by (see the appendix for details)

$$
\begin{gathered}
p(i)=p(0)(1-i)^{-(1-\alpha)} \quad \forall \quad 0 \leq i \leq J \\
p(i)=p(1) i^{-(1-\alpha)} \quad \forall \quad J<i \leq 1
\end{gathered}
$$


where $p(0)$ is the price of $y(0)$ and $p(1)$ is the price of $y(1)$. The economic intuition behind these price equations is straightforward. Consider the price of intermediate goods, which are produced with unskilled labor, as given by (32). As $i \in[0, J]$ increases, intermediate goods $y(i)$ become more expensive since the productivity of unskilled labor $l(i)$ falls with $i$. An analogous interpretation applies to $p(i)$ with $i \in[J, 1]$, as given by (33).

As has been indicated above, the pattern of sectoral productivities of skilled and unskilled labor implies that there are two groups of sectors in equilibrium. The first group produces with unskilled labor and $x_{L}$-machines, whereas the second employs skilled labor together with $x_{H}$-machines. The critical threshold $J$ can be determined from the condition $p(0)(1-J)^{-(1-\alpha)}=p(1) J^{-(1-\alpha)}$ stating that both sectors are equally profitable (for the derivation see the appendix):

$$
J=\left(1+\left(\frac{A_{H}}{A_{L}} \frac{H}{L}\right)^{1 / 2}\right)^{-1}
$$

Remember that the range of sectors employing unskilled labor is $[0, J]$. This range is accordingly smaller, the higher the skill bias of technology $\frac{A_{H}}{A_{L}}$ and the larger the relative human capital endowment $\frac{H}{L}$. The reverse holds true for the range of sectors producing with unskilled labor, as given by $[J, 1]$.

It can be shown that aggregate output, defined by $Y=\int_{0}^{1} p(i) y(i) d i$, is described by a CES technology in the primary input factors $L$ and $H$ (for the derivation see the appendix):

$$
Y=\exp (-1)\left[\left(A_{L} L\right)^{1 / 2}+\left(A_{H} H\right)^{1 / 2}\right]^{2}
$$

Notice that the (derived) elasticity of substitution between $L$ and $H$ in $Y$-production is equal to 2 .

To complete the description of the macroeconomic equilibrium, we finally report the skill bias. In the appendix it is shown that along the BGP the skill bias in the North, with endowments $H_{N}$ and $L_{N}$ of skilled and unskilled labor, respectively, is given by

$$
\frac{A_{H}}{A_{L}}=\frac{H_{N}}{L_{N}}
$$


This equation shows that the technological skill bias $\frac{A_{H}}{A_{L}}$ is positively associated with the relative skill endowment $\frac{H_{N}}{L_{N}}$. This is in fact a special case of the preceding result; see equ. (20), assuming that $\theta=2$. Combining (34) and (36), we find that the threshold sector in the North, $J_{N}$, is given by $J_{N}=\left(1+\frac{H_{N}}{L_{N}}\right)^{-1}$.

The South. The Southern economies are largely identical to the Northern economies. There are, however, two important exceptions. First, intellectual property rights cannot be enforced in the South and hence there is no R\&D in the South. Machine producers in the South can copy the blueprints invented in the North at a small fixed cost. As a result, the South operates with the range of machines as provided by the North, i.e. $\left[0, A_{L}\right]$ and $\left[0, A_{H}\right]$. Second, the South has a lower relative skill endowment, i.e. $\frac{H_{S}}{L_{S}}<\frac{H_{N}}{L_{N}}$. From (34) and (36), this implies that the threshold sector in the South $J_{S}=J=\left(1+\left(\frac{H_{N}}{L_{N}} \frac{H_{S}}{L_{S}}\right)^{1 / 2}\right)^{-1}>J_{N}$.

\subsubsection{Productivity differences}

The model set up above implies that output per worker $\left(\frac{Y}{L+H}\right)$ in the typical Southern economy is smaller than output per worker in the typical Northern economy. This result holds true despite the fact that both group of economies have access to the same technology. The economic intuition is straightforward: Southern economies use a technology mix, as given by $\left[0, A_{L}\right]$ and $\left[0, A_{H}\right]$, which has been designed according to the fundamentals of the North, but is suboptimal when applied in the South.

To illustrate the implied productivity differences consider output per worker, which can be expressed as follows (see equ. (35))

$$
\frac{Y}{L+H}=\exp (-1) \frac{\left[\left(A_{L}\right)^{1 / 2}+\left(A_{H} \frac{H}{L}\right)^{1 / 2}\right]^{2}}{1+H / L} .
$$

Figure 3 shows that output per worker is an inverse U-shaped function of $\frac{H}{L}$. Moreover, it is easy to show that this curve has a maximum at $\frac{H}{L}=\frac{A_{H}}{A_{L}}$. Considering equ. (36) shows that this condition holds true for Northern economies. Hence, the technology mix $\frac{A_{H}}{A_{L}}$ is such that labor productivity is indeed maximized in the North. Since Southern 
economies have a lower relative skill endowment, output per worker in the South falls short of output per worker in the North.

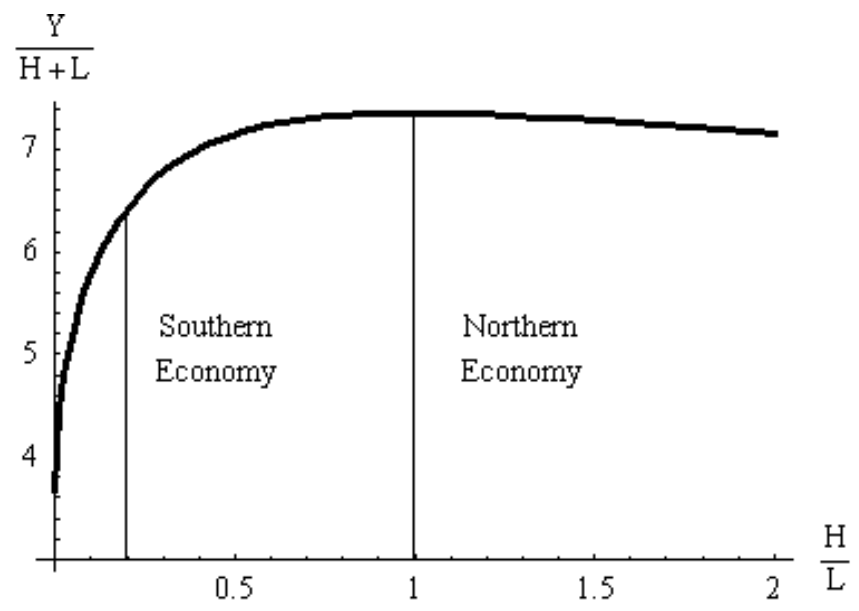

Figure 3: Output per worker as a function of relative human capital.

The reason for the productivity difference between the North and the South is a technology-skill mismatch. The North develops technologies that are most appropriate for its own needs. More specifically, the North develops more skill-biased technologies because there are relatively more skilled workers using these technologies. These Northern technologies are mismatched to the skills of the workforce in less developed economies. This can be seen more clearly from (36), which implies $A_{H}\left(1-J_{N}\right)=A_{L} J_{N}$. Considering the production function (29) immediately shows that the preceding condition states that the physical productivities of both skilled and unskilled labor are equalized. This basic efficiency condition is violated in the South since $A_{H}$ and $A_{L}$ are the same, but $J_{S}>J_{N}$.

\subsection{Trade and growth}

So far we have used horizontal innovation models to better understand economic development in isolated economies. It is clear that, in the real world, there are a number of international linkages (like goods trade, capital movements, migration of labor, and the flow of ideas via communication networks), which might have important feedback effects on the process of economic growth. In what follows we focus on the consequences of 
goods trade and the flow of ideas for economic growth. The analysis follows Rivera-Batiz and Romer (1991).

\subsubsection{The model setup}

The underlying model is basically identical to the Romer (1990) model considered above. Recall that there are three sectors on the production side. Final output is produced according to technology (2). The production of machines requires that one unit of consumption is foregone, implying that the unit cost equals $r$. This implies that final output (consumption) and machines are produced with the same technology.

Turning to the R\&D sector, we distinguish between two different specifications. The first model, labelled the knowledge-driven specification of $R \mathscr{E} D$, is the same as in the underlying base model. The R\&D technology is given by equ. (4), which is restated here for convenience

$$
\dot{A}=\eta A L_{A}
$$

The important point to notice is that technological knowledge, measured by $A$, has a direct impact on the productivity of researchers. Since the manufacturing sector (producing consumption goods and machines) and the R\&D sector use different technologies, the underlying economy belongs to the class of two-sector models.

The second specification, labelled the lab-equipment approach of $R \mathscr{E} D$, assumes that the $\mathrm{R} \& \mathrm{D}$ technology is proportional to the production function used in the manufacturing sector

$$
\dot{A}=B L_{A}^{1-\alpha} \int_{0}^{A} x_{A}(i)^{\alpha} d i
$$

where $B>0,0<\alpha<1, L_{A}$ denotes the amount of labor devoted to $\mathrm{R} \& \mathrm{D}$, and $x_{A}(i)$ is the amount of machines of type $i$ employed in R\&D. Notice that knowledge per se has no direct impact on the productivity of researchers. In contrast to the knowledge-driven specification, the lab-equipment model belongs to the class of one-sector models. If the output of manufacturing goods $(C+\dot{K})$ is reduced by one unit and the inputs released are transferred to the R\&D sector, they yield $B$ additional designs. ${ }^{26}$ Hence, this technology

\footnotetext{
${ }^{26}$ In the knowledge-driven model the production possibility frontier (PPF) between manufacturing
} 
specification fixes the price of designs at $p_{A}=1 / B$. We will see that this has important implications for the consequences of economic integration on long run growth.

\subsubsection{The interest rate and the balanced growth rate}

Before turning to the implications of economic integration, we determine the equilibrium interest rate and the balanced growth rate for the two model specifications under consideration. For the knowledge-driven specification we know from section 2.1.3 that equilibrium on the production side requires $r=\eta \alpha L-\alpha g$ (see equ. (6)), whereas equilibrium in the consumer sphere is characterized by $r=\sigma g+\rho$ (see equ. (7)). The intersection of these two equilibrium conditions determines $r$ and $g$, as illustrated in Figure 4 (a).

In the lab-equipment model, equilibrium in the consumer sphere is also described by the KRR, $r=\sigma g+\rho$. However, in contrast to the knowledge-driven model, equilibrium on the production side requires that the interest rate, $r_{\text {lab-equ }}$, is given by (see the appendix)

$$
r_{\text {lab-equ }}=\alpha^{2+(\alpha-1)}(1-\alpha)^{1-\alpha} L^{1-\alpha} B^{1-\alpha}
$$

This interest rate is obviously independent of the growth rate, as is also illustrated in Figure 4 (b). The economic reason behind this result is as follows: In the knowledgedriven model, an increase in the interest rate reduces the price of designs $p_{A}=\frac{\pi}{r} \cdot{ }^{27} \mathrm{As}$ a result, $\mathrm{R} \& \mathrm{D}$ becomes less attractive and less labor is allocated to the $\mathrm{R} \& \mathrm{D}$ sector, which slows down growth. In the lab-equipment model, on the other hand, an increase in $r$ does not affect $p_{A}=1 / B$. Put differently, in the lab-equipment model there is only one interest rate which is compatible with production of both manufacturing goods and designs.

The balanced growth rate under the knowledge-driven specification and the lab-

output $(C+\dot{K})$ and new designs $(\dot{A})$ is concave due to different factor intensities in the two sectors. In the lab-equipment model the PPF is linear.

${ }^{27}$ Notice that an increase in $r$ reduces $p_{A}$ via two channels: (i) it directly reduces $p_{A}$ due to discounting and (ii) it indirectly decreases $p_{A}$ since an increase in $r$ lowers the equilibrium sales of $x$ and hence reduces profits $\pi$. 
equipment approach, $g_{\text {know }}$ and $g_{\text {lab-equ }}$, respectively, are as follows ${ }^{28}$

$$
\begin{gathered}
g_{\text {know }}=\frac{\eta \alpha L-\rho}{\sigma+\alpha} \\
g_{\text {lab-equ }}=\frac{\alpha^{2+(\alpha-1)}(1-\alpha)^{1-\alpha} L^{1-\alpha} B^{1-\alpha}-\rho}{\sigma} .
\end{gathered}
$$

Notice that, in both cases, there is a scale effect since economic growth accelerates with the size of the labor force $L$.

Let us shortly sketch the consequences of complete economic integration of two identical economies. The integrated economy is identical to the individual economies with the exception that the labor endowment is $2 L$ instead of $L$. For both specifications the curve describing equilibrium in the production sphere shifts up, as displayed in Figure 4. As a result, both the interest rate and the growth rate increase.
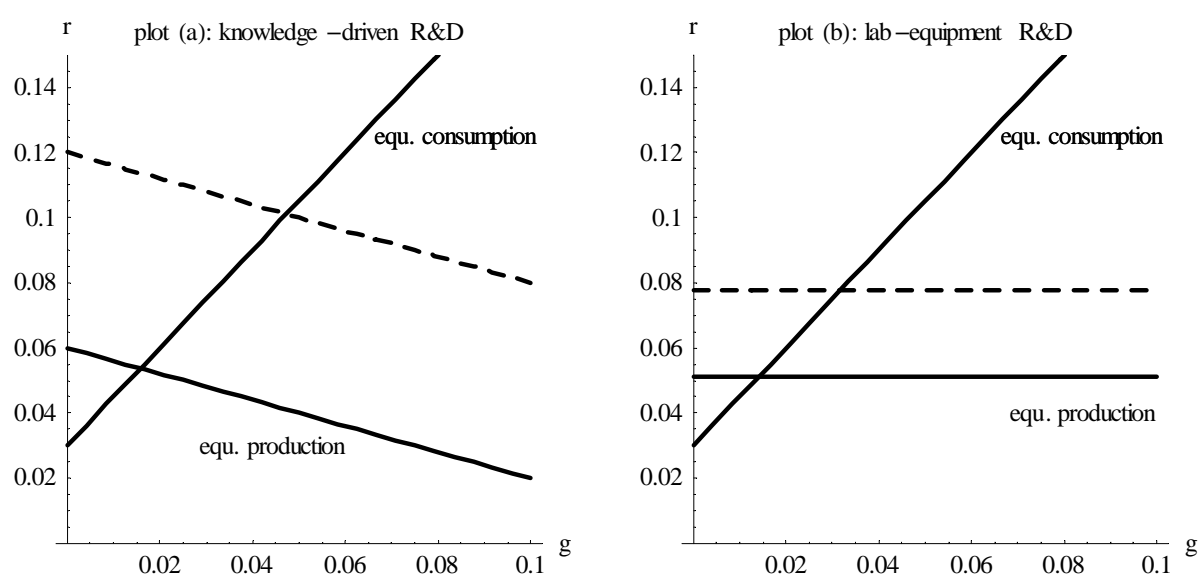

Figure 4: Long run equlibrium under knowledge-driven R\&D specification and lab-equipment specification (solid curves: autarky; dashed curves: integration).

\footnotetext{
${ }^{28}$ We assume that the growth condition is strictly satisfied in both cases such that $g>0$.
} 


\subsubsection{Three thought experiments}

We consider the consequences of partial integration (either liberalization of goods trade or flow of ideas) between two completely identical economies. ${ }^{29}$ First, using the knowledgedriven specification, we investigate the consequences of goods trade liberalization. Second, employing the same setup, we analyze the effects of additionally removing any barriers to the flow of information. Third, we use the lab-equipment approach to study the consequences of goods trade only.

Goods trade without flow of ideas in the knowledge-driven economy. Considering the R\&D technology (37) shows that the long run growth rate $g=\eta L_{A}$ is exclusively determined by the allocation of labor to R\&D. Goods trade liberalization can only have an impact on growth by affecting the intersectoral labor allocation. To simplify, we assume that both economies produce initially completely disjoint sets of machines. Then, in response to trade liberalization, the number of machines available to the manufacturing sector doubles. Considering the final output technology $Y=L_{Y}^{1-\alpha} A x^{\alpha}$ shows that the wage rate in $Y$-production under trade liberalization amounts to $w_{Y}=(1-\alpha) L_{Y}^{-\alpha} 2 A x^{\alpha}$ (the amount of $x$ along the BGP remains constant). What about the wage rate of researchers? Opening the economy to goods trade implies that the market for newly designed good is twice as large as it was in the absence of trade. As a consequence, the price of designs, everything else the same, doubles and the wage rate of researchers accordingly is $w_{R \& D}=2 p_{A} \eta A .{ }^{30}$ Since both wages increase by the same proportional amount, the allocation of labor $L=L_{Y}+L_{A}$ is not affected along the BGP and hence the long run growth rate remains constant. In terms of Figure 4 (a), goods liberalization does not affect the position of the two curves.

In summary, goods trade liberalization leaves the long run growth rate unchanged. It does, however, increase the level of the BGP due to larger gains of specialization since the number of machine varieties employed in $Y$-production doubles.

\footnotetext{
${ }^{29}$ Considering two identical economies radically simplifies the analysis. Along the BGP there cannot be any intertemporal trade in consumption goods nor can there be any intratemporal trade in homogenous consumption goods. The only trade which takes place is intratemporal trade in differentiated capital goods.

${ }^{30}$ Notice that $A$ refers to domestic knowledge only.
} 
Flows of information in the knowledge-driven model. We assume full protection of international property rights. It is further supposed that two identical economies, which have already liberalized their goods trade, remove any barriers to the flow of information. This implies that R\&D in each country can make use of the total knowledge stock $A+A^{*}=2 A$ (again we assume that both economies produce two completely disjoint sets of machines). From the R\&D technology the long run growth rate increases to $g=\eta 2 L_{A}$, provided that $L_{A}$ would remain constant. However, since the transition to a regime of full information flows increases, for a given allocation of labor, the wage rate earned in the $\mathrm{R} \& \mathrm{D}$ sector, while leaving the wage rate in manufacturing unchanged, labor shifts towards R\&D. This reallocation effect further speeds up growth.

Removing any barriers to communication doubles the stock of knowledge and hence has the same consequences on the long run growth rate of output and designs as doubling $\eta$ in the R\&D technology (see equ. (37)). The curve describing equilibrium in the production sphere accordingly shifts up. Figure 4 (a) shows that this increases both the interest rate and the growth rate. It is been argued above that complete integration affects the growth rate by replacing $L$ by $2 L$ in (40). Hence, the abolition of any barriers to information flows, assuming that goods trade has been already liberalized, has the same effect on long run growth as complete integration. ${ }^{31}$

Goods trade in the lab-equipment model. Assume, finally, that two identical economies liberalize their goods trade. As in the previous examples, opening the economy to trade in goods (i.e. trade in machines) doubles the extent of the market and hence doubles the profits earned by the typical $x$-monopolist. Everything else the same, this should also increase the price of patents $p_{A}$. However, this price is fixed by technology. The only way that the larger market can be reconciled with a fixed $p_{A}$ is if the interest rate increases. ${ }^{32}$ It is easy to show that the interest rate must increase by a factor $2^{1-\alpha}$ to keep $p_{A}$ constant (see the appendix for details). The resulting growth effect accordingly follows from substituting $r$ in $g=\frac{r-\rho}{\sigma}$ by $2^{1-\alpha} r$. Hence, goods market integration alone already exerts a growth effect in the lab-equipment model.

\footnotetext{
${ }^{31}$ The difference between complete integration on the one hand and free goods trade together with free flow of ideas is that migration of people is not allowed.

${ }^{32}$ Recall that the patent price can be sketched as $p_{A}=\frac{\pi}{r}$.
} 
In addition, it is readily shown that goods market integration is equivalent to complete integration. Inspecting (39) reveals that complete economic integration increases $r$ by a factor of $2^{1-\alpha}$; to see this replace $L$ by $2 L$ in (39). This says that, in the lab-equipment model, trade liberalization has the same growth effect as complete economic integration.

\subsubsection{Final remarks}

This section has demonstrated that international linkages can play an important role in the process of economic development. The main insight reads that economic integration may boost long run growth rate via two main channels: (i) the scale-effects channel and (ii) the factor-reallocation channel. ${ }^{33}$ As has been demonstrated, the results depend crucially on the model under study. Moreover, since the growth rate in the underlying class of models is unambiguously too low compared to the social optimum, opening up the economy is welfare improving.

In addition, it is important to stress that the previous analysis is based on the simplifying assumption of identical economies such that there are no reasons for specialization. Grossman and Helpman (1991, chapters 4 and 5) and Devereux and Lapham (1994) have shown that specialization does occur provided that there are international asymmetries. In this case, the economy which has a comparative disadvantage in the engine-of-growth sector might experience a deceleration of growth. Market integration is nonetheless likely to be welfare improving due to favorable terms-of-trade effects.

\section{Vertical Innovations}

As emphasized so far, in models of horizontal innovations economic growth is driven by new intermediate goods which generate specialization gains. In this section, we turn our focus to vertical innovations, which are directed to quality-improvements of existing goods or improvements of production processes. We start, in section 3.1, with a so-called Schumpeterian growth model which captures the notion of "creative destruc-

\footnotetext{
${ }^{33}$ If the underlying model belongs to the class of semi-endogenous growth models, then there is only a weak scale effect, i.e. a scale effect in levels (Bretschger and Steger, 2004).
} 
tion", i.e., that existing goods and firms are replaced by new ones of higher quality (Aghion and Howitt, 1992, 1998). In addition to featuring scale effects in growth rates, like the models by Romer (1990) and Grossman and Helpman (1991), the first model presented in this section has another problematic prediction in common with earlier models of endogenous technical change: it suggests that a higher intensity of product market competition reduces the incentive to conduct $\mathrm{R} \& \mathrm{D}$ and thereby retards growth. However, many empirical studies find that, if anything, more competition fosters innovation (Blundell, Griffith and van Reenen, 1999) or that the relationship between the intensity of product market competition and R\&D investments is non-monotonic (e.g. Aghion, Bloom, Blundell, Griffith and Howitt, 2005, Aghion, Blundell, Griffith, Howitt and Prantl, 2006). Later, in section 3.2, we discuss a model, based on Aghion and Howitt (2005, section 4), which is consistent with such evidence. It implies that in technologically advanced sectors incumbents have higher R\&D incentives when they face a more competitive environment, whereas the opposite occurs in less advanced sectors.

\subsection{The Aghion-Howitt model}

We start with a version of the endogenous growth model by Aghion and Howitt (1992, 1998) which captures the Schumpeterian notion of creative destruction. Higher R\&D investments raise the probability of innovations which are targeted to improve the quality of an intermediate good, replacing the current version of the intermediate input in final goods production. The current intermediate good producer has price setting power, for instance, due to a patent. However, when a new innovation arrives, the previous innovation becomes worthless for the previous innovator (business-stealing effect), even if there is a patent of infinite length. Like in Romer (1990), the expected profit stream from an innovation determines the incentive of the $R \& D$ sector to incur $R \& D$ costs.

\subsubsection{Set up}

Consider a small open economy which faces interest rate $r \geq 0$ and where instantaneous utility of individuals is linear, with future consumption being discounted at rate $(1+$ 
$r)^{-1}$. That is, individuals are risk-neutral and are indifferent between present and future consumption. There are $H$ skilled workers and $L=1$ unskilled workers. Both skilled and unskilled workers inelastically supply one unit of labor to perfect labor markets which are segmented by skill. Skilled workers can be allocated to both the R\&D sector and the intermediate goods sector, whereas unskilled workers can be employed in the final goods sector. $^{34}$

The final goods sector produces a homogenous good, chosen as numeraire. It operates under perfect competition. Output $y_{t}$ after $t$ innovations of the representative final goods producer is given by

$$
y_{t}=A_{t} x_{t}^{\alpha} L^{1-\alpha}, 0<\alpha<1,
$$

where $x_{t}$ and $A_{t}$ denote quantity and quality of the intermediate good after $t$ innovations. (Note that $t$ is not an index of calendar time but indicates the number of innovations which have occurred so far.) Each innovation raises the quality of the intermediate good by a constant factor:

$$
A_{t+1}=\gamma A_{t}, \gamma>1
$$

where $A_{0}$ is given.

After each innovation, there is an intermediate good producer (e.g. the innovator holding a patent) who can transform one unit of skilled labor into one unit of output. Marginal production costs of innovator $t$ thus equal the wage rate for skilled labor, $w_{t}$. According to (42) and $L=1$, innovator $t$ faces an inverse demand function $p_{t}=$ $\alpha A_{t} x_{t}^{\alpha-1}$. Hence, as a monopolist, maximizing $\left(p_{t}-w_{t}\right) x_{t}$ subject to $p_{t}=\alpha A_{t} x_{t}^{\alpha-1}$, he $/$ she would charge the price $p_{t}=w_{t} / \alpha$ to the final goods producer. However, assume that there are many potential competitors ("competitive fringe"), which can also produce the most recent version of the intermediate good but are less cost-efficient than the innovator. ${ }^{35}$ For instance, one may think about foreign companies possessing a design for an intermediate good which yields similar quality than that of the domestic intermediate

\footnotetext{
${ }^{34}$ By including unskilled labor in the model we extend the basic Aghion-Howitt framework in a way which allows us to study effects on the wage distribution; see section 3.1.3.

${ }^{35}$ This assumption has been employed in different contexts in a number of contributions on R\&D and growth (see e.g. Aghion and Howitt, 2005). It allows us to discuss in a simple way the role of product market competition in the proposed framework.
} 
goods producer but are less accommodated to the local environment. Fringe firms require $\chi \in(1,1 / \alpha)$ units of skilled labor per unit of output. As long as the price charged by innovator $t$ does not exceed $\chi w_{t}$, he/she still gets the entire demand; thus, the optimal price for the intermediate good producer with a one-to-one technology is $p_{t}=\chi w_{t}$, i.e., $\chi$ is the mark-up factor, which inversely captures the intensity of product market competition. Thus, in equilibrium, rivals do not enter. We may interpret a lower $\chi$ as regulatory barrier to entry for foreign firms. Alternatively, it may reflect stricter price regulation of monopoly firms.

Using demand function $p_{t}=\alpha A_{t} x_{t}^{\alpha-1}$, price $p_{t}=\chi w_{t}$ implies that innovator $t$ produces output $x_{t}=\left[\alpha /\left(\chi \omega_{t}\right)\right]^{\frac{1}{1-\alpha}}$, where $\omega_{t} \equiv w_{t} / A_{t}$. Hence, instantaneous profit $\pi_{t}=\left(p_{t}-w_{t}\right) x_{t}$ of innovator $t$ is given by

$$
\pi_{t}=A_{t}(\chi-1)(\alpha / \chi)^{\frac{1}{1-\alpha}} \omega_{t}^{-\frac{\alpha}{1-\alpha}} \equiv A_{t} \tilde{\pi}\left(\omega_{t}, \chi\right)
$$

As $\partial \tilde{\pi} / \partial \chi>0$ for all $\chi<1 / \alpha$, an increase in $\chi$ raises instantaneous profits, whereas a higher adjusted wage rate, $\omega_{t}$, negatively affects $\pi_{t}$.

The research sector is competitive. After $t$ innovations, the probability for $z$ innovations to occur in a small time interval $d \tau$ is Poisson-distributed with parameter $\mu_{t} d \tau$, i.e., is given by $e^{-\mu_{t} d \tau}\left(\mu_{t} d \tau\right)^{z} / z$ !. The probability that no innovations $(z=0)$ occur in $d \tau$ after $t+1$ innovations therefore equals $e^{-\mu_{t+1}} d \tau$. In this case, innovator $t+1$ continues to make profit $\pi_{t+1}$. Otherwise, he/she is replaced by the next innovator, which means that profits fall to zero. Parameter $\mu_{t}$ is proportional to the amount of R\&D labor employed after $t$ innovations, $h_{t}$, i.e., $\mu_{t}=\lambda h_{t}$, where $\lambda>0$ reflects the productivity of the $\mathrm{R} \& \mathrm{D}$ process. With discount rate $r \geq 0$, the value of innovation $t+1$ is given by ${ }^{36}$

$$
V_{t+1}=\int_{0}^{\infty} \pi_{t+1} e^{-\left(r+\mu_{t+1}\right) \tau} d \tau=\frac{A_{t+1} \tilde{\pi}\left(\omega_{t+1}, \chi\right)}{r+\lambda h_{t+1}}
$$

Thus, an increase in the number of future researchers after $t+1$ innovations have arrived, $h_{t+1}$, by raising the probability of innovation $t+2$, depresses the value of innovation $t+1$. To determine the R\&D input after $t$ innovations, note that the probability per unit

\footnotetext{
${ }^{36}$ As will become apparent, the amount of $\mathrm{R} \& \mathrm{D}$ labor between two innovations is time-invariant.
} 
of time that a successful innovation $t+1$ occurs, $1-e^{-\mu_{t}}$, is approximately given by $\mu_{t}=\lambda h_{t}$ (using a first-order Taylor approximation). Thus, the optimal amount of R\&D labor solves

$$
\max _{h_{t}}\left\{\mu_{t} V_{t+1}-w_{t} h_{t}\right\}=\frac{\lambda h_{t} A_{t+1} \tilde{\pi}\left(\omega_{t+1}, \chi\right)}{r+\lambda h_{t+1}}-w_{t} h_{t}
$$

Using $A_{t+1}=\gamma A_{t}$ and $\omega_{t}=w_{t} / A_{t}$, the resulting first-order condition can be written as

$$
\omega_{t}=\frac{\lambda \gamma \tilde{\pi}\left(\omega_{t+1}, \chi\right)}{r+\lambda h_{t+1}}
$$

Labor market clearing requires $h_{t}+x_{t}=H$. Thus, using $x_{t}=\left[\alpha /\left(\chi \omega_{t}\right)\right]^{\frac{1}{1-\alpha}}$, we have

$$
h_{t}+\left(\frac{\alpha}{\chi \omega_{t}}\right)^{\frac{1}{1-\alpha}}=H
$$

\subsubsection{Steady state equilibrium R\&D labor and growth}

We focus on the steady state, where $h_{t}=h^{*}$ and $\omega_{t}=\omega^{*}$ (i.e., the allocation of skilled labor does not change over time and its wage rate, $w$, grows in parallel with quality index A). Combining (47) and (48) and observing the expression for $\tilde{\pi}(\omega, \chi)$ in (44), we obtain for the steady state R\&D labor input

$$
h^{*}=\frac{\gamma(\chi-1) H-r / \lambda}{1+\gamma(\chi-1)}
$$

Before interpreting this result, note that expected output at time $\tau+1$ is $E(y(\tau+1))=$ $\mu_{t} y_{t+1}+\left(1-\mu_{t}\right) y_{t}$. As $y_{t+1}=\gamma y_{t}$ and $\mu_{t}=\lambda h^{*}$ in steady state, the average growth rate of output, $g_{y}=E(y(\tau+1)) / y_{t}-1$, becomes

$$
g_{y}=\lambda(\gamma-1) h^{*}
$$

in steady state. According to (49) and (50), we find that the average steady state rate of growth, $g_{y}$, increases with skilled labor endowment $H$, mark-up factor $\chi$, and R\&D productivity $\lambda$. 


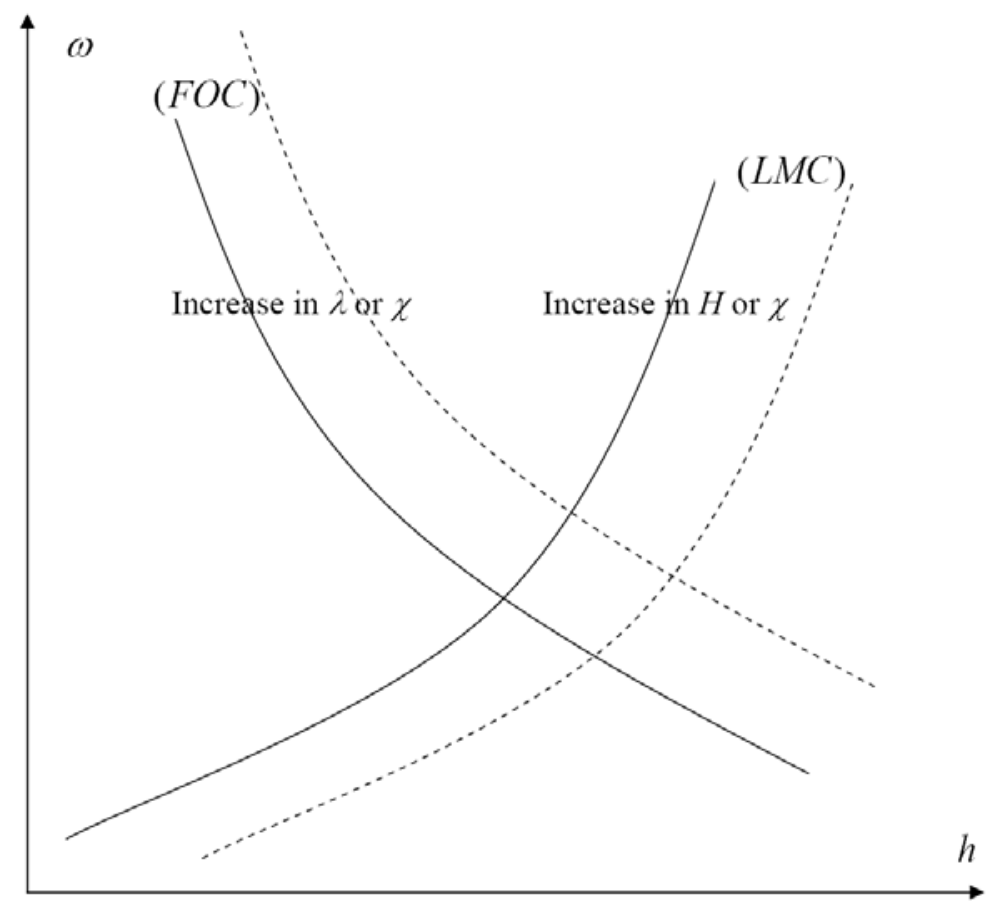

Figure 5: Comparative-static results in the creative-destruction model.

The comparative-static results in the creative destruction model can be understood with help of the $h-\omega$ diagram in Fig. 5, which gives us the steady state amount of R\&D labor, $h^{*}$, as intersection between the curves (FOC) and (LMC). The curve (FOC) shows a negative relationship between $\mathrm{R} \& \mathrm{D}$ labor, $h$, and the adjusted wage rate of skilled labor, $\omega$, implied by the first-order condition (47) for the optimal R\&D labor choice. The curve (LMC) shows a positive relationship between $h$ and $\omega$, implied by the labor market clearing condition (48).

An increase in the size of the skilled workforce, $H$, affects the labor market clearing condition. The (LMC)-curve in Fig. 5 shifts to the right, resulting in a lower productivity-adjusted long-run equilibrium wage rate, $\omega^{*}$, and a higher equilibrium amount of R\&D labor, $h^{*}$. According to (50), a higher $h^{*}$ implies a higher (average) steady state growth rate, $g_{y}$. Thus, like other first-generation endogenous growth models, the model produces scale effects in growth rates.

An increase in mark-up factor $\chi$, which captures a lower intensity of product market competition, affects both first-order condition for the optimal choice of R\&D labor (47) 
and labor market clearing condition (48). Regarding the consequences for $h^{*}$ both effects go in the same direction. First, a higher $\chi$ positively affects instantaneous profits and thereby enhances the marginal benefit to invest in $\mathrm{R} \& \mathrm{D}$. This means that (FOC)-curve in Fig. 5 shifts to the right. Second, it reduces labor input for the production of the intermediate good for any given adjusted wage rate, $\omega$. This is because a higher mark-up reduces demand for the most recent version of the intermediate good by raising its price. For a given $\omega$, this implies that more resources are available for $\mathrm{R} \& \mathrm{D}$ and therefore the (LMC)-curve shifts to the right as well. Thus, the model predicts that higher price setting power (less competition) unambiguously raises $h^{*}$ and thereby increases the economy's growth rate in long-run equilibrium, $g_{y}$. Like the scale effect prediction, this result is hard to reconcile with empirical evidence and modified in the next subsection.

Finally, an increase in R\&D productivity, $\lambda$, does not affect the (LMC)-curve but, provided $r>0$, shifts the (FOC)-curve to the right, resulting in an increase of both $\omega^{*}$ and $h^{*}$. The reason for this is as follows. On the one hand, a higher $\lambda$ raises, in the state after $t$ innovations, the probability $\mu_{t}$ to replace the current intermediate good producer by innovation $t+1$. On the other hand, however, it raises the probability for innovator $t+1$ to be replaced itself. There are thus two opposing effects on the marginal benefit to conduct R\&D. If $r>0$, the former dominates the latter. (If $r=0$, both effects cancel each other and the (FOC)-curve remains unaffected.) Together with a direct impact (for given $\mathrm{R} \& \mathrm{D}$ input) of a higher $\lambda$ on steady state growth, this implies that $g_{y}$ is increasing in $\lambda$.

\subsubsection{Steady state equilibrium wages and inequality}

It is also interesting to look more closely to the effects on wage rates for skilled and unskilled labor, adjusted for productivity. Combining (48) and (49), we find that the productivity-adjusted steady state wage for skilled labor is given by

$$
\omega^{*}=\frac{\alpha}{\chi}\left(\frac{1+\gamma(\chi-1)}{H+r / \lambda}\right)^{1-\alpha} .
$$


Moreover, from (42), the wage rate for unskilled labor, $q$, is given by $q_{t}=\partial y_{t} / \partial L=$ $(1-\alpha) A_{t} x_{t}^{\alpha}$ after $t$ innovations (recall $\left.L=1\right)$. Define $\zeta_{t} \equiv q_{t} / A_{t}$. Then, in steady state, using $x^{*}=\left[\alpha /\left(\chi \omega^{*}\right)\right]^{\frac{1}{1-\alpha}}$ and $\omega^{*}$ as given by $(51)$, we have

$$
\zeta^{*}=(1-\alpha)\left(\frac{H+r / \lambda}{1+\gamma(\chi-1)}\right)^{\alpha}
$$

We have already seen above that an increase in the skilled labor force, $H$, lowers $\omega^{*}$, whereas, if $r>0$, an increase in R\&D productivity, $\lambda$, raises $\omega^{*}$. The opposite effects hold regarding the productivity adjusted steady state wage for unskilled labor, $\zeta^{*}$. This is because an increase in $\omega^{*}$ lowers the equilibrium input of the intermediate good, which is complementary to unskilled labor in the production of the final good. Thus, $\zeta^{*}$ rises in $H$ and, if $r>0$, decreases in $\lambda$. Finally, from Fig. 5, it is evident that there are opposing effects regarding the impact of a higher mark-up factor, $\chi$, on $\omega^{*}$. Indeed, the net effect is ambiguous, according to (51). In contrast, due to the negative effect of a higher $\chi$ on demand for the intermediate good and the technological complementarity between $x$ and $L$ in producing the final good, $\zeta^{*}$ is decreasing in $\chi$.

The relative wage rate between skilled and unskilled labor is given by

$$
\frac{\omega^{*}}{\zeta^{*}}=\frac{\alpha}{1-\alpha} \frac{\gamma-(\gamma-1) / \chi}{H+r / \lambda}
$$

according to (51) and (52), and thus is increasing in $\chi$ (recall $\gamma>1$ ). Higher market power of intermediate goods producers therefore not only raises the economy's growth rate on average, but also raises wage inequality.

\subsection{Competition and $R \& D$}

This subsection modifies the prediction of many models of endogenous technical change that higher price setting power of intermediate good firms, which produce a capital input on basis of a "design" or "blueprint" created by innovators, unambiguously fosters R\&D activity. Employing panel data from British firms, Blundell, Griffith and van Reenen (1999) find that industries with lower import penetration and higher concentration levels 
generate fewer aggregate innovations. This refutes the hypothesis of the previously discussed creative-destruction model, among others, that a higher mark-up factor $\chi$ in the intermediate good sector spurs innovative effort.

At the same time, there is a large body of evidence for the famous hypothesis of Joseph A. Schumpeter that larger firms are more likely to innovate: "As soon as we go into details and inquire into the individual items in which progress was most conspicuous, the trail leads $[\ldots]$ precisely to the doors of the large concerns - [...] - and a shocking suspicion dawns upon us that big business may have had more to do with creating that standard of life than with keeping it down" (Schumpeter, 1942; reprinted 1994, p. 83). In addition to their evidence on the relationship between innovations and the intensity of product market competition across industries, Blundell, Griffith and van Reenen (1999) find that within industries firms with high market share are the most innovative ones. Also other studies strongly suggest that firm size and R\&D expenditure are strongly positively related (see e.g. Cohen and Levin, 1989, and Cohen and Klepper, 1996a,b, as well as the references therein). As stated in Cohen and Klepper (1996a, p. 929) "[...] in most industries, it has not been possible to reject the null hypothesis that R\&D varies proportionally with size across the entire firm size distribution". For instance, 81.6 percent of business R\&D expenditure in the U.S. in 1997 have been incurred by firms with more than 1000 employees (OECD, 1999, Tab. 5.4.1).

However, earlier models of endogenous technical change, by suggesting that higher intensity of competition harms innovations, cannot explain why large firms can be the main innovators in an industry and at the same time increased competition can spur innovations. We will now present a growth model with heterogeneous firms which captures this possibility, and thereby is consistent with the discussed empirical findings. It shows that incumbent firms who are technologically advanced and therefore face high demand for their products raise their R\&D effort in response to increased competition. In the remainder of this section, we heavily draw on Aghion and Howitt (2005, section 4). Their model has differentiated implications for regulatory policy. For instance, it allows us to conclude in which kind of industries domestic governments should foster or curb competition from foreign firms. 


\subsubsection{The model}

Consider a small open economy in which R\&D is adaptive in the sense that firms have to innovate in order to stay at or prevent falling more behind the technological frontier. Firms are heterogeneous with respect to their distance to the frontier technology, which evolves exogenously. Again, innovations occur with uncertainty, where the probability of successfully innovating depends on R\&D effort. For simplicity, the interest rate is zero $(r=0)$.

Suppose there is one type of labor, where the workforce $L$ is normalized to unity. Again, workers inelastically supply their labor to a perfect labor market. Labor is used exclusively for the production of a homogenous final good. The final good can not only be consumed, but can also be used as input for both the R\&D process and the production of differentiated intermediate goods. The final good (again, the numeraire) at time $t=1,2, \ldots$ is produced under perfect competition, according to

$$
y_{t}=L_{t}^{1-\alpha} \int_{0}^{1} A_{t}(i)^{1-\alpha} x_{t}(i)^{\alpha} d i
$$

$0<\alpha<1$, where $x_{t}(i)$ denotes the quantity of intermediate input $i \in[0,1]$ in period $t$ and $A_{t}(i)$ indicates the quality of the most recent version of that input. $L_{t}$ is labor input in $t$.

The technological frontier $\bar{A}_{t}$ evolves according to

$$
\bar{A}_{t}=\gamma \bar{A}_{t-1}, \gamma>1
$$

There are three types of sectors, indexed by $0,1,2$, and one firm in each sector (the incumbent). An incumbent $i$ of type 0 is at the technological frontier and has to successfully innovate to stay there. A firm of type 0 thus produces in $t-1$ an intermediate good with quality $\bar{A}_{t-1}$ and quality in $t$ is given by

$$
A_{t}(i)=\left\{\begin{array}{c}
\bar{A}_{t} \text { with probability } \mu_{0}, \\
\bar{A}_{t-1} \text { with probability } 1-\mu_{0} .
\end{array}\right.
$$


To innovate with probability $\mu_{0}$ in $t-1$ requires $\mathrm{R} \& \mathrm{D}$ expenditure (in terms of the final good) of

$$
N_{t-1}(i)=0.5\left(\mu_{0}\right)^{2} \bar{A}_{t}
$$

That is, to raise the probability of a successful innovation becomes increasingly expensive. Moreover, the required $\mathrm{R} \& \mathrm{D}$ spending rises with the targeted quality, $\bar{A}_{t}$.

A sector $i$ of type 1 is one step behind the current technological frontier. That is, in $t-1$, it has quality $\bar{A}_{t-2}$. In period $t$, analogously to (55) and (56), in a type 1 sector

$$
A_{t}(i)=\left\{\begin{array}{c}
\bar{A}_{t-1} \text { with probability } \mu_{1}, \\
\bar{A}_{t-2} \text { with probability } 1-\mu_{1},
\end{array}\right.
$$

where success probability $\mu_{1}$ requires $R \& D$ expenditure of

$$
N_{t-1}(i)=0.5\left(\mu_{1}\right)^{2} \bar{A}_{t-1}
$$

Finally, in a type 2 sector, quality in $t-1$ equals $\bar{A}_{t-3}$, i.e., a firm in this sector is two steps behind the frontier. For simplicity, to prevent those firms to fall more than two steps behind, suppose that in period $t$, a firm $i$ in a type 2 sector either automatically upgrades one step to $A_{t}(i)=\bar{A}_{t-2}$ or even catches up with the technological frontier, without any R\&D effort. That is, type 2 firms will not spend anything on R\&D. There is a constant fraction $\varepsilon$ of type 2 firms which in $t$ obtain $\bar{A}_{t}$ without innovating, by "luck". Otherwise, all firms would become type 2 firms in the long run, as type 1 firms, which are not successful in their attempt to innovate, become type 2 firms and, similarly, unsuccessful type 0 firms become type 1 firms. This is because the technological frontier grows over time (at constant rate, $\gamma-1$ ).

Again suppose there is a large number of potential competitors of the incumbent in each sector ("competitive fringe"), where the incumbent is more cost-efficient than the competitive fringe. Whereas the incumbent can transform one unit of the final good into one unit of the intermediate input (i.e., marginal costs are unity), marginal costs of the competitive fringe are given by $\chi \in(1,1 / \alpha)$. In contrast to the previously discussed 
creative-destruction model, however, the competitive fringe may not be able to perfectly imitate the quality offered by an incumbent. More precisely, assume that the fringe firms can produce intermediate good in sector $i$ with quality $\min \left\{A_{t}(i), \bar{A}_{t-1}\right\}$. That is, in a type 0 sector, the quality which the competitive fringe can offer in $t$ is $\bar{A}_{t-1}$. This means that a fringe firm can imitate only non-innovating firms, i.e., an incumbent which was of type 0 and then turns into type 1 , but not a successful innovator. In contrast, if the incumbent in a type 1 sector innovates, the competitive fringe is able to imitate even a successful innovator in a type 1 sector, i.e., again has quality $\bar{A}_{t-1}$. Otherwise, quality of a fringe firm is $\bar{A}_{t-2}$, either by imitating an unsuccessful incumbent which was of type 1 before failing to innovate or by imitating an incumbent firm which was of type 2 to begin with and was not lucky enough to upgrade its quality.

\subsubsection{Equilibrium analysis}

According to (53) and $L_{t}=L=1$, the inverse demand function for input $i$ in $t$ is $p_{t}(i)=\alpha\left(A_{t}(i) / x_{t}(i)\right)^{1-\alpha}$. In type 1 and type 2 sectors, as the competitive fringe has quality which is equal to that of the incumbent, incumbents in these sectors set prices equal to the marginal costs of the competitive fringe. Thus, $p_{t}(i)=\chi<1 / \alpha$.

Hence, in a type 2 firm, $x_{t}(i)=(\alpha / \chi)^{\frac{1}{1-\alpha}} \bar{A}_{t-2}$ and thus profits, $\pi_{t}(i)=\left(p_{t}(i)-1\right) x_{t}(i)$, become

$$
\pi_{t}(i)=(\chi-1)(\alpha / \chi)^{\frac{1}{1-\alpha}} \bar{A}_{t-2} \equiv \tilde{\pi}(\chi) \bar{A}_{t-2}
$$

For a type 1 firm, conditional on whether innovation effort is successful or not,

$$
\pi_{t}(i)=\left\{\begin{array}{c}
\tilde{\pi}(\chi) \bar{A}_{t-1} \text { with probability } \mu_{1}, \\
\tilde{\pi}(\chi) \bar{A}_{t-2} \text { with probability } 1-\mu_{1} .
\end{array}\right.
$$

Note that $\tilde{\pi}(\chi)$ is increasing in $\chi$, as $\chi<1 / \alpha$.

We now analyze the $R \& D$ decision of type 1 incumbents, who solve:

$$
\max _{\mu_{1}}\left\{\mu_{1} \tilde{\pi}(\chi) \bar{A}_{t-1}+\left(1-\mu_{1}\right) \tilde{\pi}(\chi) \bar{A}_{t-2}-0.5\left(\mu_{1}\right)^{2} \bar{A}_{t-1}\right\}
$$


according to (58) and (60). The first-order condition reads $\tilde{\pi}(\chi)\left(\bar{A}_{t-1}-\bar{A}_{t-2}\right)-\mu_{1} \bar{A}_{t-1}=$ 0. Thus, using $\bar{A}_{t-1}=\gamma \bar{A}_{t-2}$, we obtain

$$
\mu_{1}=\left(1-\frac{1}{\gamma}\right) \tilde{\pi}(\chi)
$$

which is increasing in $\chi$. Hence, for incumbents of type 1, a higher intensity of product market competition reduces $\mathrm{R} \& \mathrm{D}$ incentives. The reason is that the difference between post-innovation and pre-innovation profits, $\tilde{\pi}(\chi)\left(\bar{A}_{t-1}-\bar{A}_{t-2}\right)$, is increasing in $\chi$. In other words, the profit gain from successfully innovating declines if competitive pressure from fringe firms rises, in turn lowering R\&D incentives. In line with Aghion and Howitt (2005), we may label this as "Schumpeterian effect", although this term is rather misleading: As outlined above, Schumpeter (1942) merely suggested that larger firms conduct more $R \& D$, which may well be the case although more intense competition may lead to higher overall R\&D spending, as will become apparent.

Let us now contrast the result for type 1 firms with the R\&D decision of incumbents of type 0 . If there is no innovation, the fringe firms can offer the same quality as the incumbent. Thus, an unsuccessful type 0 incumbent again sets $p_{t}(i)=\chi$. However, if there is an innovation, potential rivals not only have higher marginal costs, $\chi>1$, but also lower quality, $\bar{A}_{t-1}<\bar{A}_{t}=A_{t}(i)$, than a successful innovator $i$ in a type 0 sector. Under assumption

$$
\alpha \chi \gamma^{1-\alpha}>1
$$

a successful innovator can then set monopoly price $p_{t}(i)=1 / \alpha$ and thus produces $x_{t}(i)=$ $\alpha^{\frac{2}{1-\alpha}} \bar{A}_{t}$, leading to profits $\pi_{t}(i)=\tilde{\pi}(1 / \alpha) \bar{A}_{t}$. To see this, note that the inverse demand function faced by all firms implies $p_{t}(i) / A_{t}(i)^{1-\alpha}=\alpha / x_{t}(i)^{1-\alpha}$. The final goods sector thus prefers the combination of price $p_{t}(i)=1 / \alpha$ and quality $A_{t}(i)=\bar{A}_{t}=\gamma \bar{A}_{t-1}$ of the successful innovator to the combination $p_{t}(i)=\chi$ and $A_{t}(i)=\bar{A}_{t-1}$ offered by the competitive fringe, if $(1 / \alpha) /\left(\gamma \bar{A}_{t-1}\right)^{1-\alpha}<\chi /\left(\bar{A}_{t-1}\right)^{1-\alpha}$, which implies assumption (63). 
Hence, under (63), for a type 0 firm $i$,

$$
\pi_{t}(i)=\left\{\begin{array}{c}
\tilde{\pi}(1 / \alpha) \bar{A}_{t} \text { with probability } \mu_{0} \\
\tilde{\pi}(\chi) \bar{A}_{t-1} \text { with probability } 1-\mu_{0}
\end{array}\right.
$$

Using (64), an incumbent $i$ in a type 0 sector solves

$$
\max _{\mu_{0}}\left\{\mu_{0} \tilde{\pi}(1 / \alpha) \bar{A}_{t}+\left(1-\mu_{0}\right) \tilde{\pi}(\chi) \bar{A}_{t-1}-0.5\left(\mu_{0}\right)^{2} \bar{A}_{t}\right\}
$$

The first-order condition reads $\tilde{\pi}(1 / \alpha) \bar{A}_{t}-\tilde{\pi}(\chi) \bar{A}_{t-1}-\mu_{0} \bar{A}_{t}=0$. Thus, using $\bar{A}_{t}=\gamma \bar{A}_{t-1}$, we obtain

$$
\mu_{0}=\tilde{\pi}(1 / \alpha)-\frac{\tilde{\pi}(\chi)}{\gamma}
$$

which is decreasing in mark-up factor $\chi$. Hence, for incumbents of type 0 , a higher intensity of product market competition raises $\mathrm{R} \& \mathrm{D}$ incentives, in contrast to what we found for a type 1 sector. The reason is that the difference between post-innovation and pre-innovation profits, $\tilde{\pi}(1 / \alpha) \bar{A}_{t}-\tilde{\pi}(\chi) \bar{A}_{t-1}$, is now decreasing in $\chi$. This is because pre-innovation rents are rising in the price setting power of incumbents, whereas a successful innovator is technologically so advanced that competition of potential rivals can be disregarded while setting prices. In this sense, an innovator of type 0 can escape competition. The effect that higher intensity of competition spurs R\&D incentives may thus be called "escape-competition" effect.

In sum, the analysis suggests that in sectors close to the "technology frontier", higher intensity of competition fosters $\mathrm{R} \& \mathrm{D}$ spending $\left(\partial \mu_{0} / \partial \chi<0\right)$, whereas for sectors more distant to the frontier, competition is harmful $\left(\partial \mu_{1} / \partial \chi>0\right)$. Also note that, as $\tilde{\pi}(1 / \alpha)>$ $\tilde{\pi}(\chi)$, we have $\mu_{0}>\mu_{1}$, according to (62) and (66). Thus, firms close to the frontier spend more on R\&D. Using assumption (63), it is easy to see that successful innovators of type 0 also sell more output than type 1 firms, despite higher prices, as their products are of sufficiently higher quality. Thus, the results are consistent with the evidence that larger firms spend more on R\&D than smaller firms.

What is the implication of the coexistence of the escape-competition effect on R\&D 
effort of technologically advanced sectors on the one hand and the Schumpeter effect on $\mathrm{R} \& \mathrm{D}$ of the more backward firms on the other hand for aggregate innovation effort? To answer this question, we have to know the equilibrium shares of type 0 and type 1 sectors in the economy, denoted by $q_{0}$ and $q_{1}$, respectively. (Recall that type 2 firms do not incur R\&D costs.)

In steady state, using that a share $\varepsilon$ of type 2 sectors exogenously catches up with the technological frontier, $q_{0}$ and $q_{1}$ are given by the equations

$$
\begin{gathered}
\underbrace{\left(1-q_{0}-q_{1}\right) \varepsilon}_{\text {entry in sector } 0}=\underbrace{q_{0}\left(1-\mu_{0}\right)}_{\text {exit from sector } 0}, \\
\underbrace{q_{0}\left(1-\mu_{0}\right)}_{\text {entry in sector } 1}=\underbrace{q_{1}\left(1-\mu_{1}\right)}_{\text {exit from sector } 1} .
\end{gathered}
$$

Solving this equation system, by using the expressions for $\mu_{1}$ and $\mu_{0}$ as given by (62) and (66), respectively, gives us the aggregate innovation rate $I=q_{0} \mu_{0}+q_{1} \mu_{1}$ as a function of $\chi$. Generally, this function can be increasing (Schumpeterian effect dominates), decreasing (escape-competition effect dominates) or non-monotonic.

A decreasing shape (higher degree of competition spurs innovation) would be consistent with the evidence by Blundell, Griffith and van Reenen (1999). In a series of papers, Aghion and coauthors find a non-monotonic, U-shaped relationship between the competitive pressure on British firms from foreign companies and the average innovation rate. Obviously, given the two opposing forces from firms close and more distant to the frontier, the selection of firms within a sample matters for the observed relationship between competition and average innovation. 


\section{R\&D-based Growth with Horizontal and Vertical Differentiation}

In this section we present a version of the model by Young (1998) which is representative for a class of models featuring both horizontal and vertical differentiation of products. ${ }^{37}$ It is particularly designed to remove scale effects with respect to the economy's growth rate. Unlike semi-endogenous growth models, it is capable to generate positive long-run growth without scale effects in growth rates even in absence of population growth. We also present a simple extension of the model which introduces credit market imperfections in the spirit of a recent paper by Aghion, Howitt and Mayer-Foulkes (2005). We show how the economy's rate of growth depends on the degree of financial development. In particular, we argue that there can be divergence between developed and less developed countries, i.e., poorer economies grow slower than richer economies.

\subsection{The Young model}

\subsubsection{Set up}

Consider an economy which is populated by $L$ identical individuals with infinite lifetimes, each supplying one unit of labor in each period $t=0,1,2, \ldots$ (i.e., there is no population growth). The labor market is perfect and the wage rate is normalized to unity, $w_{t}=1$. There is a representative consumer with intertemporal utility function

$$
U=\sum_{t=0}^{\infty} \rho^{t} \ln C_{t}
$$

$0<\rho<1 . C_{t}$ is a consumption index in the spirit of Dixit and Stiglitz (1977), which is given by

$$
C_{t}=\left(\int_{0}^{n_{t}}\left[A_{t}(i) x_{t}(i)\right]^{\frac{\sigma-1}{\sigma}} d i\right)^{\frac{\sigma}{\sigma-1}}
$$

\footnotetext{
${ }^{37}$ See also Peretto (1998), Segerstrom (1998) and Dinopoulos and Thompson (1999) for models that capture similar ideas. Illuminating discussions of this class of models can be found in Jones (1999) and Lainez and Peretto (2006).
} 
$\sigma>1$, where $x_{t}(i)$ denotes the quantity of variety $i \in\left[0, n_{t}\right]$ consumed in period $t$, and $A_{t}(i)$ indicates its quality.

Each firm produces one variety of the horizontally differentiated product in monopolistic competition. The measure $n_{t}$ is referred to as the number of firms and goods in $t$ and is endogenously determined for $t \geq 1$. One unit of labor can be transformed into one unit of output of each variety, i.e., marginal production costs equal the wage rate and therefore are unity.

Following Young (1998), firms can incur in-house R\&D labor investments in order to improve product quality one period in advance of production. Denote by $l_{t-1}(i)$ the amount of R\&D employed by firm $i \in\left[0, n_{t}\right]$ in $t-1$. Product quality $A_{t}(i)$ of variety $i$ in any period $t \geq 1$ evolves according to

$$
A_{t}(i)=\bar{A}_{t-1} z\left(l_{t-1}(i)\right)
$$

where $z$ is an increasing function with $z(0)=1$ and $\bar{A}_{t-1}=\frac{1}{n_{t-1}} \int_{0}^{n_{t-1}} A_{t-1}(i) d i$ is the average product quality level in $t-1$, reflecting the state of technology in $t-1$. $\bar{A}_{0}>0$ is given. According to (71), knowledge acquired by R\&D activity is private information of a firm (e.g., due to intellectual property rights) for one period only. This is for simplicity. Moreover, if all firms invest the same amount in R\&D, the number of firms does not matter for research capabilities of firms in the subsequent period. This assumption reflects the notion of Young (1998) that innovations of firms are 'equivalent' in the sense that firms come up with similar solutions to similar problems at the same time. It contributes to the removal of scale effects in growth rates.

There is free entry of firms into the economy, with a large number of potential entrants. Firms may have to incur a fixed labor requirement $f \geq 0$ prior to production, which may be thought of being related to red tape or the organization of production. In $t-1$, each firm $i$ producing final output in period $t$ issues bonds or shares in order to finance fixed costs $f$ as well as R\&D investment. The financial market is perfect (an assumption which is relaxed below). 


\subsubsection{Equilibrium analysis}

Let us start with the static utility maximization. According to (70), for a given aggregate nominal consumption expenditure $E_{t}$, the demand function for good $i$ in period $t$ is given by

$$
x_{t}(i)=\frac{E_{t} p_{t}(i)^{-\sigma} A_{t}(i)^{\sigma-1}}{\left(P_{t}\right)^{1-\sigma}},
$$

where $p_{t}(i)$ is the price of good $i$ in $t$ and

$$
P_{t} \equiv\left(\int_{0}^{n_{t}}\left[p_{t}(i) / A_{t}(i)\right]^{1-\sigma} d i\right)^{\frac{1}{1-\sigma}}
$$

is a price index. This implies $C_{t}=E_{t} / P_{t}$, i.e., $C_{t}$ equals "real" consumption. Next consider intertemporal maximization of utility (69) subject to $a_{t+1}=\left(1+r_{t}\right) a_{t}+L-E_{t}$ (recall $w_{t}=1$ ), $t \geq 0$, where $a_{t}$ denotes asset holding in $t$ and $r_{t}$ denotes the interest rate in $t$ ( $a_{0}$ and $r_{0}$ are given). Using $\ln C_{t}=\ln E_{t}-\ln P_{t}$, for all $t \geq 1$, we find that consumption spending evolves according to the Euler equation

$$
E_{t}=\left(1+r_{t}\right) \rho E_{t-1}
$$

Profits of firm $i$ in period $t$ are given by $\pi_{t}(i)=\left(p_{t}(i)-1\right) x_{t}(i)$. Using (72), optimal prices are thus given by $p_{t}(i)=\sigma /(\sigma-1) \equiv p^{*}$ for all $i$ and $t$. At time $t-1$, each firm $i \in\left[0, n_{t}\right]$ chooses R\&D labor investments $l_{t-1}(i)$ to maximize its firm value $\pi_{t}(i) /(1+$ $\left.r_{t}\right)-l_{t-1}(i)-f$. Using $(71)-(73)$ together with $p_{t}(i)=p^{*}=\sigma /(\sigma-1)$, the optimization problem can be written as

$$
\max _{l_{t-1}(i) \geq 0}\left\{\frac{E_{t} / \sigma}{1+r_{t}} \frac{\left[\bar{A}_{t-1} z\left(l_{t-1}(i)\right)\right]^{\sigma-1}}{\int_{0}^{n_{t}} A_{t}(i)^{\sigma-1} d i}-l_{t-1}(i)-f\right\} .
$$

We focus on an interior solution. Sufficient conditions are that

$$
\lim _{l \rightarrow 0} z^{\prime}(l) \rightarrow \infty \text { and }(\sigma-2) z^{\prime}(l) / z(l)+z^{\prime \prime}(l) / z^{\prime}(l)<0 \text { for all } l>0 .
$$

The latter condition in (76) ensures that the second-order condition for a maximum is 
fulfilled. (It holds, for instance, if $\sigma \leq 2$ and $z^{\prime \prime}<0$.) Under assumption (76), there is a symmetric choice of $l_{t-1}$ and thus $A_{t}(i)=\bar{A}_{t}=\bar{A}_{t-1} z\left(l_{t-1}\right)$ for all $i$. The first-order condition associated with problem (75) can therefore be written as

$$
(\sigma-1) \frac{E_{t} / \sigma}{1+r_{t}} \frac{z^{\prime}\left(l_{t-1}\right)}{z\left(l_{t-1}\right)}=n_{t}
$$

Free entry implies that in equilibrium the firm value is zero. Thus, under symmetry,

$$
\frac{E_{t} / \sigma}{1+r_{t}}=n_{t}\left(l_{t-1}+f\right)
$$

according to (71) and (75). Combining (77) and (78), we find that equilibrium R\&D investment per firm, $l^{*}$, is time-invariant and implicitly given by

$$
(\sigma-1) \frac{z^{\prime}\left(l^{*}\right)}{z\left(l^{*}\right)}\left(l^{*}+f\right)=1
$$

The latter condition in assumption (76) implies that the left-hand side of (79) is strictly decreasing in $l^{*}$. Hence, there exists a unique equilibrium R\&D investment level $l^{*}>0$.

The equilibrium growth rate of product quality, $g_{\bar{A}}$, is given by $g_{\bar{A}}=z\left(l^{*}\right)-1$, according to (71). Clearly, there are no transitional dynamics in this model. Moreover, as will become apparent, $g_{\bar{A}}$ is also the growth rate of "real consumption level", $C_{t}=E_{t} / P_{t}$. As an important result, as $l^{*}$ is independent of population size $L$, there is no scale effect in the equilibrium rate of growth of product quality, $g_{\bar{A}}$.

The absence of scale effects in growth rates is driven by two properties: First, the number of firms in $t, n_{t}$ does not matter for the state of technology in $t, \bar{A}_{t}$, in symmetric equilibrium. Second, $n$ turns out to be proportional to $L$ in equilibrium and therefore leaves R\&D investment per firm unaffected. To see the latter, combine (74) and (78) to find that $n_{t}\left(l_{t-1}+f\right)=\rho E_{t-1} / \sigma$. Also note that consumption expenditure $E_{t}=n_{t} p^{*} x_{t}$ in symmetric equilibrium and therefore $n_{t-1} x_{t-1}=(\sigma-1) E_{t-1} / \sigma$. Thus, full employment condition $n_{t}\left(l_{t-1}+f\right)+n_{t-1} x_{t-1}=L$ implies

$$
E_{t-1}=E^{*}=\frac{\sigma L}{\sigma-1+\rho}
$$


for nominal equilibrium expenditure. Consequently, according to (74), the equilibrium interest rate is given by $r_{t}=r^{*}=(1-\rho) / \rho$ for all $t \geq 1$. More importantly, substituting (80) into $n_{t}\left(l^{*}+f\right)=\rho E^{*} / \sigma$, the equilibrium number of firms is given by

$$
n_{t}=n^{*}=\frac{\rho}{\sigma-1+\rho} \frac{L}{l^{*}+f}
$$

Thus, the number of firms is proportional to population size $L$. This result is consistent with evidence recently provided by Lainez and Peretto (2006).

Despite the absence of scale effects in growth rates, and in contrast to the semiendogenous growth model by Jones (1995), the model allows for positive long-run (exponential) growth even without population growth. This also means that the long-run growth rate does generally not respond to public policy like R\&D subsidies. ${ }^{38}$

\subsubsection{Scale effect in levels}

Using (73) together with $C_{t}=E^{*} / P_{t}$ and $p^{*}=\sigma /(\sigma-1)$, in equilibrium real consumption reads $C_{t}^{*}=E^{*}\left(n^{*}\right)^{\frac{1}{\sigma-1}} \bar{A}_{t}(\sigma-1) / \sigma$. Thus, using (80), real consumption per capita in equilibrium, $c_{t}^{*}=C_{t}^{*} / L$, is given by

$$
c_{t}^{*}=\frac{\sigma-1}{\sigma-1+\rho}\left(n^{*}\right)^{\frac{1}{\sigma-1}} \bar{A}_{t} .
$$

Hence, the growth rate of real consumption per capita, $g_{c}$, equals $g_{\bar{A}}=z\left(l^{*}\right)-1$. However, although there are no scale effects in growth rates, there are scale effects in per capita levels, like in other growth models "without" scale effects (e.g. Dinopoulos and Thompson, 1998; Jones, 1995a,b; Peretto, 1998, Segerstrom, 1998). Clearly, according to (82), as the equilibrium number of firms, $n^{*}$, is increasing in $L$, so is $c_{t}^{*}$. For instance, market integration between two economies of equal size $L$ would double the number of available products in each economy, thereby raising $c_{t}^{*}$ and thus increasing per capita utility. This is due to the property that an utility index of the Dixit-Stiglitz type like

\footnotetext{
${ }^{38}$ One can show that $R \& D$ subsidies are ineffective to raise growth rates in this model only in the special case when there are no fixed costs, $f=0$ (Grossmann, 2007a), which is the case exclusively considered in the original model by Young (1998).
} 
(70) captures "love-of-variety". ${ }^{39}$ It is analogous to the specialization gains captured by the production function for final goods in models of horizontal innovations (e.g. Romer, 1990). ${ }^{40}$

We conclude the discussion of the Young-model by noting that, according to (79) and (81), higher fixed costs $f$ are associated with a higher R\&D investment per firm, $l^{*}$, and larger firm size, $L / n^{*}$, in equilibrium. That is, larger firms invest more in R\&D. Grossmann (2007a) argues that for this reason, endogenous advertising expenditure, even if combative in nature, are associated with higher R\&D spending per firm and thereby may foster economic growth.

\subsection{Financial development and growth}

We now attempt to capture in a simple way some insights by Aghion, Howitt and MayerFoulkes (2005) on the link between financial development and R\&D-based growth. For this purpose, suppose that, rather than being able to borrow freely, potential firms can invest at most an amount $\eta \bar{A}_{t-1}$ at time $t-1$ for setting up a firm and for R\&D, where $\eta>0$. Thus, as the economy grows, the investment limit relaxes. Parameter $\eta$ captures the stage of financial development relative to the stage of economic development, the latter being measured by $\bar{A}_{t-1}$. Thus, $\eta$ may be viewed as reflecting the quality of financial institutions.

Clearly, if $\eta \bar{A}_{t-1}<l^{*}+f$, the borrowing constraint is binding and each firm invests $l_{t-1}=\eta \bar{A}_{t-1}-f$ in R\&D. Thus, $\bar{A}_{t} / \bar{A}_{t-1}=z\left(\eta \bar{A}_{t-1}-f\right)<z\left(l^{*}\right)$. Moreover, analogously to the derivation of (81), we find that employment per firm in $t$ is given by $L / n_{t}=$ $\eta \bar{A}_{t-1}(\sigma-1+\rho) / \rho$. Thus, compared to the case without credit constraints, there are more and smaller firms and the growth rate, $g_{c}=g_{\bar{A}}$, is lower. As the economy develops, for any given $\eta$, both the rate of economic growth and the size of firms increase over time. Moreover, as long as firms are credit-constrained, for any stage of economic development $\bar{A}_{t-1}$, both the rate of economic growth $\left(g_{\bar{A}}\right)$ and the size of firms $\left(L / n_{t}\right)$ increase with

\footnotetext{
${ }^{39}$ According to (70), in symmetric equilibrium, $C_{t}=n_{t}^{\frac{1}{\sigma-1}}\left(n_{t} x_{t}\right) \bar{A}_{t}$. Thus, for a given total amount of goods, $n_{t} x_{t}$, utility index $C_{t}$ increases with the number of available varieties, $n_{t}$.

${ }^{40}$ For further discussion on scale effects in levels versus growth rates, see e.g. Dinopoulos and Thompson (1998) and Jones (1999).
} 
the quality of financial institutions, $\eta$. If an economy becomes sufficiently rich, the investment limit does not matter anymore for economic growth (and the growth rate again becomes $z\left(l^{*}\right)-1$ ). These predictions are well in line with empirical evidence (see Aghion, Howitt and Mayer-Foulkes, 2005).

In sum, the extended model with credit constraints predicts that economies which have weak financial institutions (captured by a low $\eta$ ) and/or are poor economically (captured by a low $\bar{A}_{t-1}$ ) grow slower than more developed economies. This relates the observation of economic divergence between rich and poor countries (see Fig. 2) to the quality of financial institutions.

\section{Conclusion}

Understanding $R \& D$ incentives of firms is crucial for explaining long-run growth and designing public policy which is conducive for economic development. In this survey, we have focused on the model structure of seminal contributions in the theory of endogenous growth and discussed some important issues and applications.

Most notably, we presented the structure of the horizontal innovation model by Romer (1990), the vertical innovation model by Aghion and Howitt (1992) and, representative for frameworks in which goods are both horizontally and vertically differentiated, the model by Young (1998). We have focused on issues like the scale effect (e.g. Jones, 1995a,b, 1999), directed technological change (e.g. Acemoglu, 1998, 2002), appropriate technology with an innovating North and an imitating South (Acemoglu and Zilibotti, 2001), trade and growth (e.g. Rivera-Batiz and Romer, 1991), competition and R\&D (e.g. Blundell, Griffith and van Reenen, 1999; Aghion, Bloom, Blundell, Griffith and Howitt, 2005, Aghion, Blundell, Griffith, Howitt and Prantl, 2006), and the role of imperfect capital markets for R\&D-based growth (Aghion, Howitt and Mayer-Foulkes, 2005).

The issues we treated should be taken as an illustration of the usefulness of R\&Dbased growth theory, as the list of important applications is far from being exhaustive. For instance, recent developments in the theory of endogenous technical change which we 
have left out due to space constraints include the role for R\&D-based growth of the income distribution (e.g. Zweimüller, 2000; Föllmi and Zweimüller, 2006), macroeconomic volatility (e.g. Aghion, Angeletos, Banerjee and Manova, 2005), and domestic savings (e.g. Aghion, Comin and Howitt, 2006). Finally, it is evident from our analysis that both the stock of human capital and the protection of intellectual property rights are important for growth. Thus, it is intriguing to endogenize both human capital formation (e.g. Eicher, 1995, Grossmann, 2007b) and intellectual property rights institutions (Eicher and Garcia-Penalosa, 2006) in a R\&D-based growth framework.

\section{Appendix}

\subsection{Directed technical change}

Derivation of equ. (20). The production technologies (11) and (12) may be expressed as

$$
\begin{gathered}
Y_{L}=L^{1-\alpha} A_{L} x_{L}^{\alpha}, \\
Y_{H}=H^{1-\alpha} A_{H} x_{H}^{\alpha} .
\end{gathered}
$$

Plugging the demand for machines $x_{L}$ and $x_{H}((15)$ and (16)) into (83) and (84) and noting that, in equilibrium, $p_{x_{L}}^{D}=p_{x_{L}}^{S}=\frac{\psi}{\alpha}$ and $p_{x_{H}}^{D}=p_{x_{H}}^{S}=\frac{\psi}{\alpha}$ yields

$$
\begin{gathered}
Y_{L}=L^{1-\alpha} A_{L}\left(\frac{\alpha^{2} p_{L}}{\psi}\right)^{\frac{\alpha}{1-\alpha}} L^{\alpha}=L A_{L}\left(\frac{\alpha^{2} p_{L}}{\psi}\right)^{\frac{\alpha}{1-\alpha}}, \\
Y_{H}=H^{1-\alpha} A_{H}\left(\frac{\alpha^{2} p_{H}}{\psi}\right)^{\frac{\alpha}{1-\alpha}} H^{\alpha}=H A_{H}\left(\frac{\alpha^{2} p_{H}}{\psi}\right)^{\frac{\alpha}{1-\alpha}} .
\end{gathered}
$$

Using these two equations to substitute $Y_{H}$ and $Y_{L}$ in (13) gives

$$
\frac{p_{H}}{p_{L}}=\left(\frac{1-\gamma}{\gamma}\right)^{\frac{\varepsilon(1-\alpha)}{\theta}}\left(\frac{H A_{H}}{L A_{L}}\right)^{\frac{-(1-\alpha)}{\theta}}
$$

where $\theta:=1+(\varepsilon-1)(1-\alpha)$.

From (17) and (18) the profit of the typical $x_{H}$-monopolist relative to the profit of 
the typical $x_{L}$-monopolist reads

$$
\frac{\pi_{H}}{\pi_{L}}=\frac{\left(\frac{\psi}{\alpha}-\psi\right)\left(\frac{\alpha^{2}}{\psi}\right)^{\frac{1}{1-\alpha}} p_{H}^{\frac{1}{1-\alpha}} H}{\left(\frac{\psi}{\alpha}-\psi\right)\left(\frac{\alpha^{2}}{\psi}\right)^{\frac{1}{1-\alpha}} p_{L}^{\frac{1}{1-\alpha}} L}=\left(\frac{p_{H}}{p_{L}}\right)^{\frac{1}{1-\alpha}} \frac{H}{L}
$$

Along a BGP with $\dot{A}_{L}>0$ and $\dot{A}_{H}>0$ the condition $\eta_{L} \pi_{L}=\eta_{H} \pi_{H}$ must hold and hence

$$
\left(\frac{p_{L}}{p_{H}}\right)^{\frac{1}{1-\alpha}}=\frac{\eta_{H}}{\eta_{L}} \frac{H}{L}
$$

Noting (87) we find

$$
\frac{A_{H}}{A_{L}}=\left(\frac{\eta_{H}}{\eta_{L}}\right)^{\theta}\left(\frac{H}{L}\right)^{\theta-1}\left(\frac{1-\gamma}{\gamma}\right)^{\varepsilon} .
$$

This is equ. (20) in the main text.

Derivation of equ. (23). From $w_{L} L=(1-\alpha) Y_{L} p_{L}$ and $w_{H} H=(1-\alpha) Y_{H} p_{H}$ one gets

$$
\frac{w_{H}}{w_{L}}=\frac{L}{H} \frac{p_{H}}{p_{L}} \frac{Y_{H}}{Y_{L}}
$$

From (85) and (86) we have $\frac{Y_{H}}{Y_{L}}=\frac{H A_{H}}{L A_{L}}\left(\frac{p_{H}}{p_{L}}\right)^{\frac{\alpha}{1-\alpha}}$ and hence

$$
\frac{w_{H}}{w_{L}}=\frac{A_{H}}{A_{L}}\left(\frac{p_{H}}{p_{L}}\right)^{\frac{1}{1-\alpha}} .
$$

Using (87) to eliminate $\frac{p_{H}}{p_{L}}$ gives

$$
\frac{w_{H}}{w_{L}}=\left(\frac{1-\gamma}{\gamma}\right)^{\frac{\varepsilon}{\theta}}\left(\frac{A_{H}}{A_{L}}\right)^{\frac{\theta-1}{\theta}}\left(\frac{H}{L}\right)^{-\frac{1}{\theta}} .
$$

This is equ. (23) in the main text.

Derivation of equ. (22). Next we substitute $\frac{A_{H}}{A_{L}}$ in (87) according to (20) to get

$$
\frac{p_{H}}{p_{L}}=\left(\frac{\eta_{H}}{\eta_{L}}\right)^{-(1-\alpha)}\left(\frac{H}{L}\right)^{-(1-\alpha)} .
$$

Profits in the market for designs directed to unskilled labor, where the price of designs 
is denoted by $P_{A_{L}}$, are given by $P_{A_{L}} \eta R_{L}-R_{L}$ (using $\dot{A}_{L}=\eta R_{L}$ ). Using that profits are zero under free entry together with $P_{A_{L}}=\frac{\pi_{L}}{r}$, we find $\frac{\pi_{L}}{r}=\frac{1}{\eta_{L}}$. Thus, noting (17), one gets

$$
\frac{\left(\frac{\psi}{\alpha}-\psi\right)\left(\frac{\alpha^{2}}{\psi}\right)^{\frac{1}{1-\alpha}} p_{L}^{\frac{1}{1-\alpha}} L}{r}=\frac{1}{\eta_{L}} .
$$

At next we determine the equilibrium solution for $p_{L}$. This then yields the equilibrium solution for $r$, and, when combined with the KRR, gives the equilibrium long run growth rate. From (14) we have

$$
\gamma^{\varepsilon} p_{L}^{1-\varepsilon}+(1-\gamma)^{\varepsilon} p_{H}^{1-\varepsilon}=1
$$

Substituting $p_{H}=\left(\frac{\eta_{H}}{\eta_{L}}\right)^{-(1-\alpha)}\left(\frac{H}{L}\right)^{-(1-\alpha)} p_{L}$ from (88) and using $-(1-\varepsilon)(1-\alpha)=\theta-1$ yields

$$
p_{L}=\left(\gamma^{\varepsilon}+(1-\gamma)^{\varepsilon}\left(\frac{\eta_{H}}{\eta_{L}}\right)^{\theta-1}\left(\frac{H}{L}\right)^{\theta-1}\right)^{\frac{1}{-(1-\varepsilon)}} .
$$

Inserting $p_{L}$ into (89), using $-(1-\varepsilon)(1-\alpha)=\theta-1$, solving for $r$ and rearranging terms finally yields

$$
r=\left(\frac{\psi}{\alpha}-\psi\right)\left(\frac{\alpha^{2}}{\psi}\right)^{\frac{1}{1-\alpha}}\left(\gamma^{\varepsilon}\left(\eta_{L} L\right)^{\theta-1}+(1-\gamma)^{\varepsilon}\left(\eta_{H} H\right)^{\theta-1}\right)^{\frac{1}{\theta-1}}
$$

This is equ. (22) in the main text.

\subsection{Appropriate technology}

Intermediate goods prices $p(i)$. The labor market is perfectly competitive and hence labor earns its marginal product. Moreover, the wage rate for each type of labor ( $l$ and h) must be the same across different sectors. By noting (29) this gives

$$
\begin{gathered}
w_{L}=(1-\alpha) p(i)^{\frac{1}{1-\alpha}} A_{L}(1-i), \\
w_{H}=(1-\alpha) p(i)^{\frac{1}{1-\alpha}} A_{H} i .
\end{gathered}
$$


Dividing $(93)$ and $(94)$ by $w_{L}=(1-\alpha) p(0)^{\frac{1}{1-\alpha}} A_{L}$ and $w_{H}=(1-\alpha) p(1)^{\frac{1}{1-\alpha}} A_{H}$, respectively, we have

$$
\begin{gathered}
1=\frac{p(i)^{\frac{1}{1-\alpha}}(1-i)}{p(0)^{\frac{1}{1-\alpha}}} \quad \Longrightarrow \quad p(i)=p(0)(1-i)^{-(1-\alpha)} \quad \forall \quad 0 \leq i \leq J, \\
1=\frac{p(i)^{\frac{1}{1-\alpha}} i}{p(1)^{\frac{1}{1-\alpha}}} \quad \Longrightarrow \quad p(i)=p(1) i^{-(1-\alpha)} \quad \forall \quad J<i \leq 1 .
\end{gathered}
$$

Equilibrium employment. From $p(i) y(i)=p(0) y(0)=p(1) y(1)$ (resulting from profit maximization in final output production), (95), (96) and the full employment conditions $\int_{0}^{J} l(i)=L$ and $\int_{J}^{1} h(i)=H$ it follows that

$$
\begin{gathered}
l(i)=\frac{L}{J} \quad \forall \quad 0 \leq i \leq J, \\
h(i)=\frac{H}{1-J} \quad \forall \quad J<i \leq 1 .
\end{gathered}
$$

The threshold sector (equ. (34)). In the threshold sector $i=J$ it must be the case that both technologies are equally profitable, which implies

$$
p(0)(1-J)^{-(1-\alpha)}=p(1) J^{-(1-\alpha)} .
$$

Consequently,

$$
\frac{J}{1-J}=\left(\frac{p(1)}{p(0)}\right)^{\frac{1}{1-\alpha}} .
$$

Moreover, from $p(0) y(0)=p(1) y(1)$, noting (26), (97) and (98), we obtain

$$
\left(\frac{p(0)}{p(1)}\right)^{\frac{1}{1-\alpha}}=\frac{A_{H} H}{A_{L} L} \frac{J}{1-J}
$$

Noting (99) one gets

$$
\frac{J}{1-J}=\left(\frac{A_{L} L}{A_{H} H}\right)^{\frac{1}{2}} .
$$


Hence, $J$ is given by

$$
J=\left(1+\left(\frac{A_{H} H}{A_{L} L}\right)^{1 / 2}\right)^{-1}
$$

This is equ. (34) in the main text.

Determination of prices $p(0)$ and $p(1)$. From $\exp \left(\int_{0}^{1} \ln p(i) d i\right)=1$ (stating that aggregate output is chosen as the numeraire) one gets

$$
\int_{0}^{1} \ln p(i) d i=0
$$

Using (95) and (96) yields

$$
\int_{0}^{J} \ln \left(p(0)(1-i)^{-\beta}\right) d i+\int_{J}^{1} \ln \left(p(1) i^{-\beta}\right) d i=0 .
$$

Integrating the LHS and solving for $p(0)$ gives

$$
p(0)=\exp \left(\frac{\alpha-1}{J}\right)(1-J)^{\frac{J-1+\alpha(1-J)}{J}} J^{\alpha-1} p(1)^{\frac{J-1}{J}}
$$

Using $\frac{p(1)}{p(0)}=\left(\frac{J}{1-J}\right)^{1-\alpha}$ together with the preceding equation to determine $p(0)$ and $p(1)$ finally leads to

$$
\begin{gathered}
p(0)=\exp (\alpha-1) J^{\alpha-1} \\
p(1)=\exp (\alpha-1)(1-J)^{\alpha-1} .
\end{gathered}
$$

Aggregate production (equ. (35)). Using $Y=\int_{0}^{1} p(i) y(i) d i$ and noting (29), (97) and (98) we have

$$
Y=\int_{0}^{1} p(i)^{\frac{1}{1-\alpha}}\left[A_{L}(1-i) l(i)+A_{H} i h(i)\right] d i
$$

which can be rewritten as

$$
Y=\int_{0}^{J} p(i)^{\frac{1}{1-\alpha}} A_{L}(1-i) \frac{L}{J} d i+\int_{J}^{1} p(i)^{\frac{1}{1-\alpha}} A_{H} i \frac{H}{1-J} d i .
$$


Substituting $p(i)$ according to (95) and (96) and rearranging terms gives us

$$
Y=p(0)^{\frac{1}{1-\alpha}} A_{L} L+p(1)^{\frac{1}{1-\alpha}} A_{H} H
$$

Substituting $p(0)$ and $p(1)$ according to (101) and (102) and simplifying yields

$$
Y=\exp (-1)\left[\left(A_{L} L\right)^{1 / 2}+\left(A_{H} H\right)^{1 / 2}\right]^{2}
$$

This is equ. (35) in the main text.

The factor bias $\frac{A_{H}}{A_{L}}$ (equ. (36)). Substituting prices in (30) and (31) according to $(95)$ and (96) gives

$$
\begin{gathered}
\pi_{L}=(1-\alpha) \alpha \int_{0}^{J}\left(p(0)(1-i)^{-(1-\alpha)}\right)^{\frac{1}{1-\alpha}}(1-i) l(i) d i=(1-\alpha) \alpha p(0)^{\frac{1}{1-\alpha}} L \\
\pi_{H}=(1-\alpha) \alpha \int_{J}^{1}\left(p(1) i^{-(1-\alpha)}\right)^{\frac{1}{1-\alpha}} i h(i) d i=(1-\alpha) \alpha p(1)^{\frac{1}{1-\alpha}} H .
\end{gathered}
$$

Balanced growth with $\frac{A_{H}}{A_{L}}=$ const. requires $\pi_{L}=\pi_{H}$ (both sectors have the same R\&D technology, i.e. it takes the same number of units of final output to find a new blueprint; the economy grows along a BGP from the beginning such that $r$ is constant) and hence

$$
(1-\alpha) \alpha p(0)^{\frac{1}{1-\alpha}} L=(1-\alpha) \alpha p(1)^{\frac{1}{1-\alpha}} H
$$

which gives us

$$
\frac{H}{L}=\left(\frac{p(0)}{p(1)}\right)^{\frac{1}{1-\alpha}}=\left(\frac{\exp (\alpha-1) J^{\alpha-1}}{\exp (\alpha-1)(1-J)^{\alpha-1}}\right)^{\frac{1}{1-\alpha}}=\frac{1-J}{J}
$$

Using (100) we have

$$
\frac{A_{H}}{A_{L}}=\frac{H}{L}
$$

This is equ. (36) in the main text. 


\subsection{Trade and growth}

The interest rate in the lab-equipment model (equ. (39)). As has been noted above, the lab-equipment model is basically a one sector model where total output can be viewed to be produced by a single sector

$$
C+\dot{K}+\frac{\dot{A}}{B}=L^{1-\alpha} \int_{0}^{A} x(i)^{\alpha} d i
$$

Each representative firm in this sector chooses the demand for $x(i)$ so as to maximize profits. Noting the general symmetry among the $x(i)$, the inverse demand function may be expressed as

$$
p_{x}(x)=\alpha L^{1-\alpha} x^{\alpha-1}
$$

Machine producers choose the supply of $x$ so as to maximize the PDV of profits $\frac{\pi}{r}=\frac{\left(p_{x}(x)-r\right) x}{r}$. The first-order condition of this maximization problem is

$$
\frac{\alpha^{2} L^{1-\alpha} x^{\alpha-1}}{r}-1=0
$$

which, by noting (105), implies $p_{x}=\frac{r}{\alpha}$ (which is, of course, the same result as for the case of suppliers choosing an optimal supply price). Moreover, under free entry the equilibrium price of a design must satisfy $p_{A}=\max _{x}\left\{\frac{p_{x} x}{r}-x\right\}$. Substituting $p_{x}$ on the RHS by $p_{x}=\frac{r}{\alpha}$ gives

$$
p_{A}=\frac{x}{\alpha}-x=\left(\frac{1-\alpha}{\alpha}\right) x
$$

Now since $p_{A}=\frac{1}{B}$ (lab-equipment approach), one can determine the equilibrium amount of $x$ to read

$$
x=\frac{\alpha}{B(1-\alpha)} .
$$

Substituting $x$ in (105) by the preceding expression yields

$$
\frac{\alpha^{2} L^{1-\alpha}\left(\frac{\alpha}{B(1-\alpha)}\right)^{\alpha-1}}{r}-1=0,
$$


which can be rewritten as

$$
r=\alpha^{2+(\alpha-1)} L^{1-\alpha} B^{1-\alpha}(1-\alpha)^{1-\alpha} .
$$

This is equ. (39) in the main text.

Flows of goods in the lab-equipment model. The demand for $x$-machines is given by

$$
x=\left(\frac{p_{x}}{\alpha L^{1-\alpha}}\right)^{\frac{1}{\alpha-1}} .
$$

The typical $x$-monopolist who charges a price of $p_{x}$ under integration faces a demand $x_{\text {int }}$ according to

$$
x_{\mathrm{int}}=2\left(\frac{p_{x}}{\alpha L^{1-\alpha}}\right)^{\frac{1}{\alpha-1}} .
$$

The inverse demand curve accordingly reads

$$
p_{x}=\alpha L^{1-\alpha}\left(\frac{1}{2} x_{\mathrm{int}}\right)^{\alpha-1}
$$

The price of designs (assuming balanced growth at each point in time) is given by

$$
p_{A}=\frac{\pi}{r}=\frac{p_{x}(x) x_{\mathrm{int}}}{r}-x_{\mathrm{int}}=\frac{\alpha L^{1-\alpha}\left(\frac{1}{2}\right)^{\alpha-1} x_{\mathrm{int}}^{\alpha}}{r}-x_{\mathrm{int}} .
$$

Now since the equilibrium amount of $x_{\text {int }}$ is independent of the size of the market (see (107)), it remains constant. Thus the preceding equation immediately shows that for $p_{A}$ to remain constant, the interest rate must increase by a factor $2^{1-\alpha}$.

\section{References}

Acemoglu, D. (1998). Why do new technologies complement skills? Directed technical change and wage inequality, Quarterly Journal of Economics 113, 1055-1090.

Acemoglu, Daron (2002). Directed technical change, Review of Economic Studies 69, 781-809.

Acemoglu, D. and F. Zilibotti (2001). Productivity differences, Quarterly Journal of 
Economics 116, 563-606.

Aghion, P., G.-M. Angeletos, A. Banerjee and K. Manova (2005). Volatility and growth: Credit constraints and productivity-enhancing investment, Harvard University (mimeo).

Aghion, P., N. Bloom, R. Blundell, R. Griffith and P. Howitt (2005). Competition and innovation: An inverted U relationship, Quarterly Journal of Economics 120, 701728.

Aghion, P., R. Blundell, R. Griffith, P. Howitt and S. Prantl (2006). The effects of entry on incumbent innovation and productivity, NBER Working Paper No. 12027.

Aghion, P., D. Comin and P. Howitt (2006). When does domestic saving matter for economic growth?, Harvard University (mimeo).

Aghion, P. and Howitt, P. (1992). A model of growth through creative destruction, Econometrica, 60, 323-352.

Aghion, P. and Howitt, P. (1998). Endogenous Growth Theory, MIT Press, Cambridge (Ma.).

Aghion, P. and Howitt, P. (2005). Growth with quality-improving innovations: An integrated framework, in: P. Aghion and S. Durlauf (eds.), Handbook of Economic Growth, North-Holland, Amsterdam.

Aghion, P., P. Howitt and D. Mayer-Foulkes (2005). The effect of financial development on convergence: theory and evidence, Quarterly Journal of Economics 120, 173-222.

Arrow, K.J. (1962). The economic implications of learning by doing, Review of Economic Studies 29, 155-173.

Backus, D., K., P. J. Kehoe, and T. J. Kehoe (1992). In search of scale effects in trade and growth, Journal of Economic Theory 58, 377-409.

Barro, R. J. and X. Sala-i-Martin (2004). Economic Growth, MIT Press, Cambridge (Ma.).

Bernanke, B.S and R.S. Gürkaynak (2001). Is growth exogenous? Taking Mankiw, Romer, and Weil seriously, NBER Macroeconomics Annual.

Blundell, R., R. Griffith and J. van Reenen (1999). Market share, market value and innovation in a panel of British manufacturing firms, Review of Economic Studies 66, 
$529-554$.

Bretschger, L. and T. M. Steger (2004). The dynamics of economic integration: Theory and policy, International Economics and Economic Policy 1, 119-134.

Caselli, F. (2005). Accounting for cross-country income differences, in: P. Aghion and S. Durlauf (eds.), Handbook of Economic Growth, North-Holland, Amsterdam.

Chiang, A.C. (1992). Elements of Dynamic Optimization, McGraw Hill, New York.

Cohen, W.M. and S. Klepper (1996a). A reprise of firm size and R\&D, Economic Journal 106, 925-951.

Cohen, W.M. and S. Klepper (1996b). Firm size and the nature of innovation within industries: The case of process and product R\&D, Review of Economics and Statistics $78,232-243$.

Cohen, W.M. and R.C. Levin (1989). Empirical studies of innovation and market structure, in: Schmalensee, R., Willig, R. D. (eds.), Handbook of Industrial Organization, Vol. II, North-Holland, Amsterdam, ch. 18.

Devereux, M.B., Lapham, B.J. (1994). The stability of economic integration and endogenous growth, Quarterly Journal of Economics 109, 299-305.

Dinopoulos, E. and P. Thompson (1998). Schumpeterian growth without scale effects, Journal of Economic Growth 3, 313-335.

Dixit, A. and J.E. Stiglitz (1977). Monopolistic Competition and Optimum Product Diversity, American Economic Review 67, 297-308.

Eicher, T.S. (1996). Interaction between endogenous human capital and technological change, Review of Economic Studies 63, 127-44.

Eicher, T.S. and C. Garcia-Penalosa (2006). Endogenous strength of intellectual property rights: Implications for economic development and growth, University of Washington (mimeo).

Eicher, T.S. and S.J. Turnovsky (1999), Non-scale models of economic growth, Economic Journal 109, 394-415.

Ethier, W.J. (1982). National and international returns to scale in the modern theory of international trade, American Economic Review 72, 389-405.

Föllmi, R. and J. Zweimüller (2006). Income distribution and demand-induced inno- 
vations, Review of Economic Studies 73, 941-960.

Gancia, G. and F. Zilibotti (2005). Horizontal Innovation in the Theory of Growth and Development, in: P. Aghion and S. Durlauf (eds.), Handbook of Economic Growth, North-Holland, Amsterdam.

Griliches, Z. (1991). The search for R\&D spill-overs, Scandinavian Journal of Economics 94, 29-47.

Grossman, G. and E. Helpman (1991). Innovation and Growth in the Global Economy, MIT Press, Cambridge (Ma.).

Grossmann, V. (2007a). Advertising, in-house R\&D, and growth, Oxford Economic Papers, forthcoming.

Grossmann, V. (2007b). How to promote R\&D-based growth? Public education expenditure on scientists and engineers versus R\&D-subsidies, Journal of Macroeconomics, forthcoming.

Hornstein, A., P. Krusell, and G. Violante (2005). The effects of technical change on labor market inequalities, in: P. Aghion and S. Durlauf (eds.), Handbook of Economic Growth, North-Holland, Amsterdam.

Jones, C.I.. (1995a). R\&D-based models of economic growth, Journal of Political Economy 103, 759-784.

Jones, C.I. (1995b). Time series tests of endogenous growth models, Quarterly Journal of Economics 110, 495-525.

Jones, C.I. (1999). Growth: with or without scale effects?, American Economic Review 89, 139-44.

Jones, C.I. (2002). Sources of U.S. economic growth in a world of ideas, American Economic Review 92, 220-239.

Jones, C.I. (2005). Growth and ideas, in: P. Aghion and S. Durlauf (eds.), Handbook of Economic Growth, North-Holland, Amsterdam.

Jones, C. I. and Williams, J. C. (2000), Too much of a good thing? The economics of investment in R\&D, Journal of Economic Growth 5, 65-85.

Khan, B.Z. and K.I. Sokoloff (2001). The early development of intellectual property rights institutions in the United States, Journal of Economic Perspectives 15, 1-15. 
Kremer, M. (1993). Population growth and technological change: One million B.C. to 1990, Quarterly Journal of Economics 108, 681-716.

Lainez, C.A. and P.F. Peretto (2006). Scale effects in endogenous growth theory: an error of aggregation not specification, Journal of Economic Growth 11, 263-288.

Maddison, A. (2003). The World Economy: Historical Statistics, OECD, Paris.

Mankiw, N.G., D. Romer and D.N. Weil (1992). A contribution to the empirics of economic growth, Quarterly Journal of Economics 107, 407-437.

Mokyr, J. (2005). Long-term economic growth and the history of technology, in: Aghion, P. and S.N. Durlauf (eds.), Handbook of Economic Growth, North-Holland, Amsterdam.

OECD (1999). Science, Technology and Industry Scoreboard 1999: Benchmarking Knowledge-based Economies, Paris.

Rivera-Batiz, L.A. and P.M. Romer (1991). Economic integration and endogenous growth, Quarterly Journal of Economics 106, 531-555.

Romer, P.M. (1986). Increasing returns and long-run growth, Journal of Political Economy 94, 1002-1037.

Romer, P.M. (1990). Endogenous technological change, Journal of Political Economy 98, 71-101.

Schumpeter, J.A. (1942). Capitalism, Socialism and Democracy, reprinted 1994, Routledge, London.

Segerstrom, P.S. (1998). Endogenous growth without scale effects, American Economic Review 88, 1290-1310.

Smith, A. (1776). An Inquiry into the Nature and Causes of the Wealth of Nations, Fifth edition (1789), republished from: Edwin Cannan's annotated edition, 1904, Methuen \& Co., Ltd. First edition: 1776.

Solow, R.M. (1956). A contribution to the theory of economic growth, Quarterly Journal of Economics 70, 65-94.

Solow, R.M. (2000). Growth Theory: An Exposition, Oxford University Press, Oxford.

Steger, T. M. (2005). Welfare implications of non-scale R\&D-based growth models, 
Scandinavian Journal of Economics 107, 737-757.

Strulik, H. (2005). Too Much of a Good Thing? The Quantitative Economics of R\&D-driven Growth Revisited, Discussion Papers 05-26, University of Copenhagen. Department of Economics.

Swan, T. (1956). Economic growth with capital accumulation, Economic Record 32, 344-361.

Young, A. (1998) Growth without scale effects, Journal of Political Economy 106, 41-63. 